\title{
La colonización fenicia inicial en el Mediterráneo Central: nuevas excavaciones arqueológicas en Utica (Túnez)
}

\author{
The initial Phoenician colonization in Central Mediterranean: new archaeological \\ excavations in Utica (Tunisia)
}

\author{
José Luis López Castroa, Ahmed Ferjaoui ${ }^{b}$, Alfredo Mederos Martín', Víctor Martínez \\ Hahnmüller $^{d}$ e Imed Ben Jerbania ${ }^{b}$
}

\section{RESUMEN}

Se presentan los primeros resultados del proyecto de investigación tunecino-español en Utica (Túnez). En concreto se estudia un complejo formado por un pozo de agua vinculado a un edificio excavado en parte. El pozo posiblemente fue clausurado y cegado de forma ritual. El contenido de su interior ha aportado, además de abundantes restos faunísticos, un depósito de cerámicas fenicias, griegas geométricas, sardas, libias, villanovianas y tartesias, principalmente formado por vajilla de mesa y ánforas, que testimonian tempranas redes de intercambio fenicias en el Mediterráneo Central y Occidental así como un temprano asentamiento fenicio. Las dataciones de C14 obtenidas con semillas del interior del pozo aportan una cronología hacia 925-900 cal AC al conjunto material, idéntica a las de tempranos asentamientos fenicios en la Península Ibérica como Huelva, El Carambolo y La Rebanadilla. En conjunto definen el horizonte más antiguo de la colonización fenicia en el Mediterráneo Central y Occidental.

\section{ABSTRACT}

This paper presents the first results of the TunisianSpanish research project in Utica (Tunisia), in particular the finds recovered from a well (possibly closed ritually) linked to a partially excavated building. The well's interior is a deposit composed of bones of consumed animals and Phoenician, Geometric Greek, Sardinian, Lybian, Villanovaan and Tartessian pottery, principally formed by drinking cups and plates, as well as amphorae. The finds bear witness to early Phoenician networks of exchange in the Central and Western Mediterranean and to a very ancient Phoenician settlement. The dates of C14 obtained from seeds from the well's fill indicate a chronology around 925-900 cal BC. These dates are identical to those of early Phoenician foundations in the Iberian Peninsula at Huelva, Carambolo and La Rebanadilla. As a whole they define the most ancient horizon of the Phoenician colonization in Central and Western Mediterranean.

Palabras clave: Colonización fenicia temprana; Utica; Norte de África; Cerámica fenicia; Cerámica griega geométrica; Cerámica nurágica; Cerámica villanoviana; Inicios del I milenio a.C.; Dataciones de C14.

Key words: Early Phoenician colonization; Utica; North Africa; Phoenician pottery; Greek Geometric pottery; Nuraghic pottery; Villanovian pottery; Early $1^{\text {st }}$ millennium BC; $C 14$ dates.

\footnotetext{
a Dpto. de Geografía, Historia y Humanidades. Universidad de Almería. La Cañada de San Urbano s/n. 04120 Almería. España. Correo e.jllopez@ual.es

b Institut National du Patrimoine. 4 Place du Château. 1008 Tunis.Túnez. Correo e. ferjaouiahmed@yahoo.fr; ibenjerbania@ yahoo.fr

${ }^{c}$ Dpto. de Prehistoria y Arqueología. Universidad Autónoma de Madrid. Ciudad Universitaria de Cantoblanco. 28049 Madrid. España. Correo e. alfredo.mederos@uam.es

d Philipps-Universität Marburg. Fachbereich Geschichte und Kulturwissenschaften. Vorgeschichtliches Seminar. Biegenstraße 11 35037 Marburg. Alemania. Correo e.vmh232@ual.es

Recibido 13-III-2015; aceptado 15-V-2015.
} 


\section{LAS INVESTIGACIONES EN UTICA}

El yacimiento arqueológico de Utica se encuentra al Norte de Túnez en los $37^{\circ} 03^{\prime} 31 \mathrm{~N}$ y $10^{\circ} 03$ ' 47 E (Fig. 1). La antigua Utica fue, según las fuentes clásicas, una de las más antiguas fundaciones tirias en el Mediterráneo Occidental. De acuerdo con el Pseudo Aristóteles (Mir Ausc 134), una fuente del siglo III a.C., la fundación de Utica tuvo lugar 285 años antes de la fundación de Cartago, siguiendo las propias tradiciones fenicias, esto es c. 1105 a.C., si contamos el 820 a.C. como la fundación de Cartago según el cómputo de Flavio Josefo (Contra Apion I, 18; Alvar y Wagner 1985: 80-82). Posteriormente, Veleio Paterculo (I, $2,3)$, que escribió su obra en 30 d.C. anota que Utica se fundó poco después de la fundación de Gadir, la cual tuvo lugar 80 años después de la caída de Troya, en 1103 a.C. (Sánchez Manzano 2001: 50). Por su parte Plinio el Viejo (Nat. His. XVI, 216) recoge la tradición de la gran antigüedad de las vigas de cedro del templo de Apolo en Utica, el primer edificio erigido en la ciudad, que cifraba en 1178 años antes de que él escribiera, esto es, hacia 1110 a.C., pues Plinio murió en 79 d.C. (Serbat 1995: 23).

A pesar de la antigüedad atribuida por las fuentes clásicas, las excavaciones efectuadas en Utica en los siglos XIX y primera mitad del XX no aportaron datos que se remontasen más allá de finales del siglo VIII a.C., concretamente los ajuares funerarios de las necrópolis fenicio-púnicas excavadas por Cintas $(1951,1954)$ y Colozier (1954). Los cambios en la configuración del promontorio de Utica, situado en la Antigüedad en el hoy desaparecido estuario del río Bagradas (Paskoff y Trousset 1992) (Fig. 1), en su relieve original y sobre todo, las modificaciones efectuadas en el mismo por los programas del urbanismo romano no hicieron sino complicar la localización del núcleo fenicio original. Asimismo los trabajos de Lézine (1968: 103) en la ciudad romana revelaron restos constructivos de época tardopúnica y le permitieron localizar un área del hábitat antiguo con niveles del siglo VI a.C. en el foro. Posteriormente, a partir de los años 80, se realizaron excavaciones y sondeos por parte de Chelbi y Redissi que permanecen inéditas, salvo un estudio sobre la fase más antigua de las excavaciones de Redissi en 2005-2007 (Ben Jerbania y Redissi 2014).

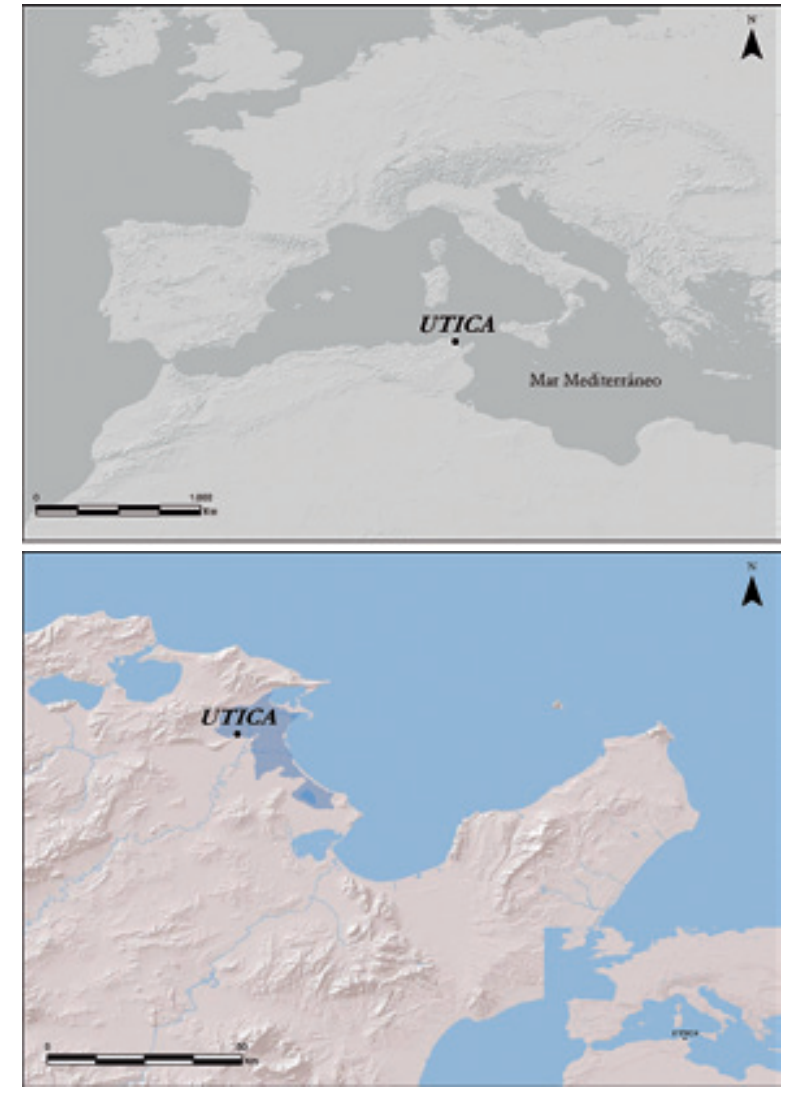

Fig. 1. Localización de Utica y reconstrucción de la antigua línea de costa (elaboración propia a partir de Paskoff y Trousset 1992).

\subsection{El proyecto tunecino-español en Utica}

En 2010 se reinició la investigación en Utica con el desarrollo de un proyecto internacional auspiciado por el gobierno tunecino a través del Institute National du Patrimoine (INP). En el participan un equipo tunecino-británico del INP y la Universidad de Oxford, centrado en la investigación de la ciudad romana de Utica (Hay et al. 2010) y en la localización del puerto romano, otro tunecino-francés del INP y la Universidad de la Sorbona-París IV dedicado a la localización del antiguo puerto fenicio (Monchambert et al. 2013) y un equipo tunecino-español que estudia la ciudad fenicio-púnica, formado por investigadores del INP y de diversas universidades españolas agrupados en el Centro de Estudios Fenicios y Púnicos. El proyecto continuará hasta 2016 y puede renovarse por periodos de tres años. El área de 


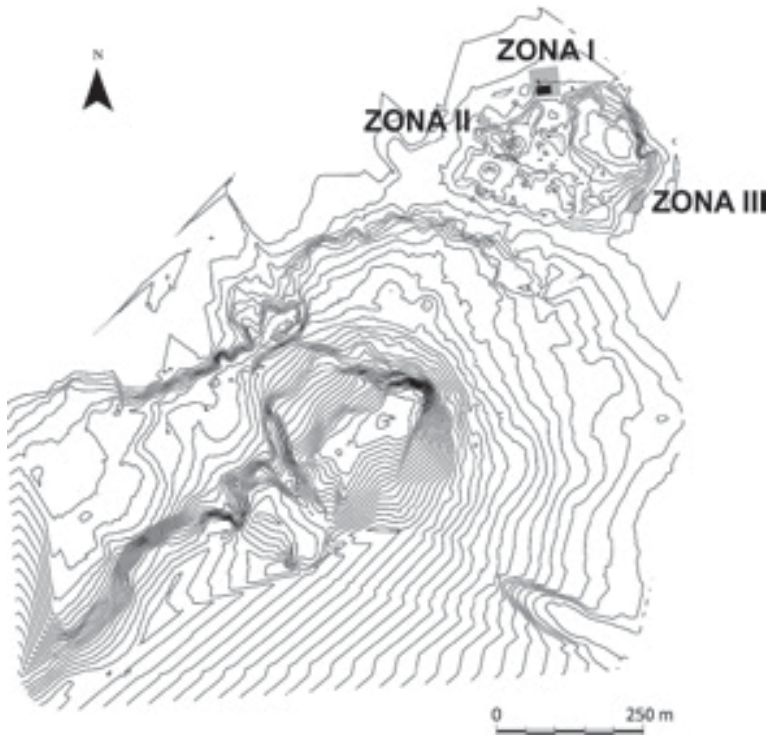

Fig. 2. Áreas de investigación del proyecto tunecinoespañol en Utica y localización de áreas de prospección geofísica (gris) y cortes arqueológicos (negro). Equidistancia de curvas $1 \mathrm{~m}$.

investigación del equipo tunecino-español se extiende por la zona norte del yacimiento, al borde de la antigua línea de costa (Fig. 2) del I milenio a.C. y las construcciones de época romana (Paskoff y Trousset 1992; Chelbi et al. 1995: 47-51) y próxima a las excavaciones de Redissi de 20052007. Los trabajos se iniciaron en 2010 con una campaña de prospección geofísica mediante $G P R$ (radar de subsuelo) efectuada por el Instituto Andaluz de Geofísica de Granada en tres zonas del yacimiento (López Castro et al. 2010), que resultaron de una extraordinaria utilidad para plantear las campañas de excavación de 2012, 2013 y 2014 centradas en dos zonas, las denominadas I y II (López Castro et al. 2014).

En este trabajo presentamos los primeros resultados de la excavación aún en curso del complejo constructivo de la fase por ahora más antigua de la Utica fenicia, descubierto en los cortes 20 y 21 de la Zona II (Fig. 2), en concreto los relativos al contenido de un pozo con abundante material cerámico fenicio, griego geométrico, sardo y libio del que se ofrece una selección representativa. Asimismo, por su interés para la cronología de la presencia fenicia en el Mediterráneo centro occidental y los inicios de la Edad del Hierro en este área geográfica, damos a conocer una serie de tres dataciones absolutas de $\mathrm{C} 14$ obtenidas a partir de muestras del mismo contexto arqueológico.

\section{EL EDIFICIO DEL CORTE 21 Y EL POZO DEL CORTE 20}

\subsection{Estado actual de la investigación}

Las campañas de excavación efectuadas en Utica en 2012, 2013 y 2014 han localizado en la Zona II de la prospección geofísica un complejo arquitectónico fenicio de gran antigüedad, aún en fase de excavación, en los cortes 20 y 21 , situados a escasos $100 \mathrm{~m}$ de la antigua línea de costa, en el límite norte de la colina del yacimiento (Fig. 2). Los trabajos agrícolas, el trazado de una vía férrea que lo recorre y el expolio al que ha sido sometido históricamente debieron destruir las edificaciones romanas y fenicio-púnicas, que sin embargo sí se localizan en los alrededores y de las que apenas quedan trazas de cimentaciones y fosas de expolio en el área de los cortes 20 y 21 . El complejo constructivo se encuentra en una cota muy superficial, y está alterado por las intervenciones mencionadas. Está formado por un edificio que está aún por excavar, parcialmente delimitado al Sur por un muro con orientación Noreste-Suroeste (UE 21085) (Fig. 3). Al interior de la construcción se documentó un pavimento (UE 21088/21094) de cantos rodados y piedras de pequeño tamaño cortado al Norte por una gran fosa romana (UE 21081) que sigue aproximadamente la orientación del edificio y destruyó parte de la estratificación existente. Al Este de la construcción y tras su ángulo sureste, formado por muros de adobes (UE 21082 y 21093) se disponía un espacio abierto donde se localizaron dos hornos domésticos de adobes (UE 21011 y UE 21026) sobre un estrato de nivelación (UE 20107/21028). Al Sur del edificio, por debajo de los estratos UE 21003 y 21061, y sus equivalentes UE 20003 y 20011, que señalan el fin del uso de esta construcción, se abre un profundo pozo de planta aproximadamente circular, de unos $3 \mathrm{~m}$ de diámetro, excavado en el sustrato natural arcilloso. El pozo, cuya excavación aún no ha concluido, alcanza los 3,94 $\mathrm{m}$ de profundidad desde la superficie (1,18 m s.n.m.) (Fig. 4). En la campaña de 2014 se llegó el nivel freático a los 


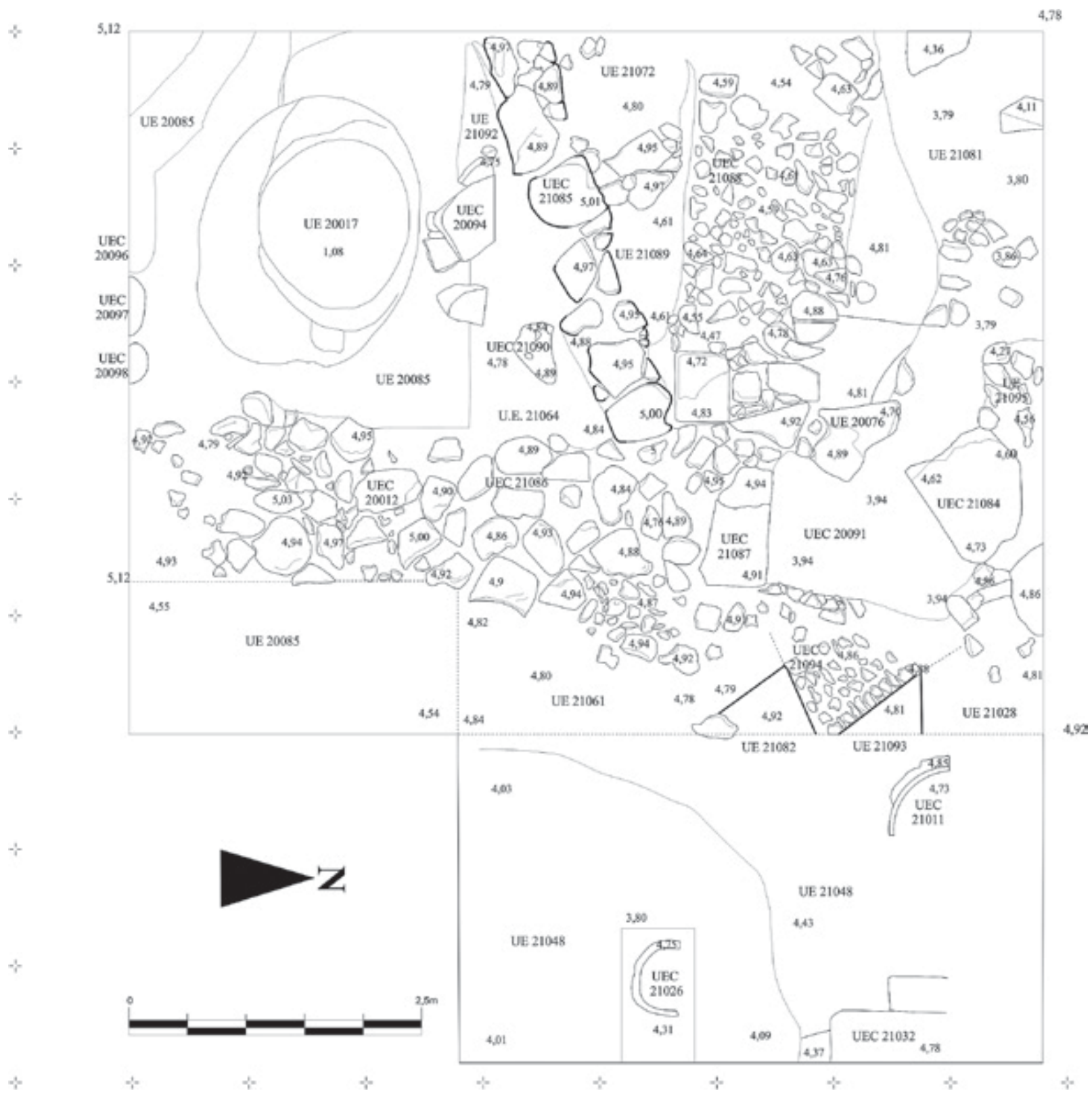

Fig. 3. Utica. Planta de los cortes 20 y 21.

2,46 m s.n.m., lo que obliga a trabajar extrayendo el agua a diario mediante una bomba.

La parte superior del pozo estaba cubierta por la base de mampuestos de un pavimento de una construcción posterior, quizá fenicio-púnica (UE 20012), así como por grandes sillares de piedra (UE 20093 y 20094) y por una fosa reciente (UE 20005) (Fig. 5), relacionada con la ocupación temporal del yacimiento por la población local allí refugiada, a causa de las grandes inundaciones de 1981.

Desde el inicio de su excavación el pozo mostró un abundante contenido antrópico formado por cerámicas fenicias, sardas, griegas geométricas, villanovianas y locales, así como numerosos restos faunísticos y algunos constructivos de es- 


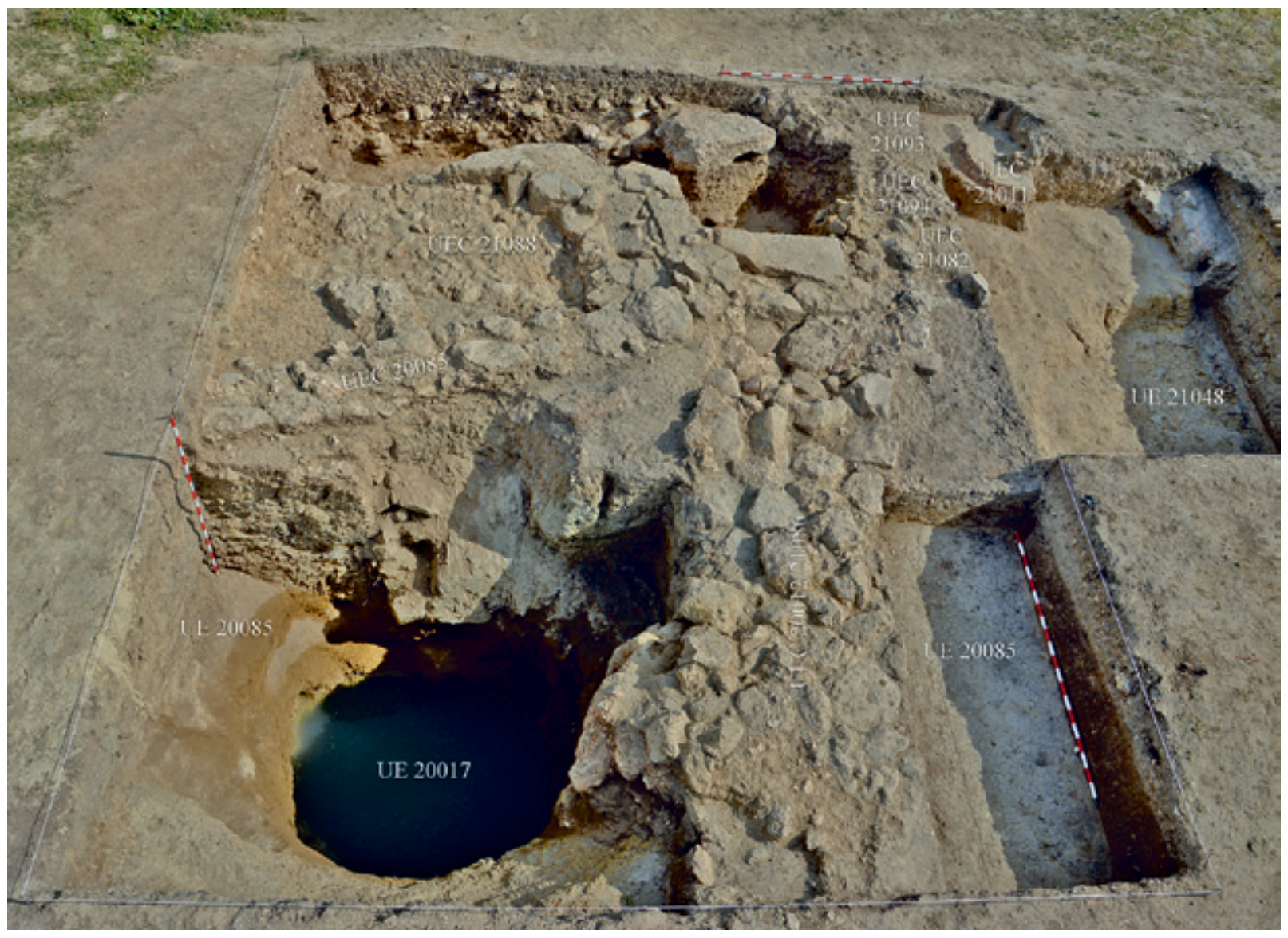

Fig. 4. Utica. Vista de los cortes 20 y 21.

casa entidad como adobes y restos de cal. Todo ello estaba compactado con tierra manchada por cenizas y carbones. Fragmentos de los mismos vasos se depositaron a diferentes profundidades dentro del pozo como un plato fenicio (Fig. 6: 10) cuyas partes integrantes aparecieron entre los 3,69 y los 3,54 m o un skyphos (Fig. 7: 7) fragmentos del cual se recuperaron de los 4,09 a los $3,48 \mathrm{~m}$ de profundidad. Además se documentaron restos óseos en conexión anatómica. Todo ello unido a la gran homogeneidad cronológica del conjunto cerámico nos está indicando que el pozo se rellenó intencionadamente en un corto lapso de tiempo. La funcionalidad de la mayor parte de los vasos cerámicos depositados, principalmente contenedores de líquidos y servicio de mesa, junto con la naturaleza del conjunto faunístico (restos de bóvidos, ovicápridos y suidos consu- midos $^{1}$ ), apunta a la vinculación del pozo con actividades rituales.

La hipótesis que cobra más fuerza en el estado actual de la investigación del complejo es que posiblemente se trataría de un pozo para la obtención de agua dulce, un water pit de la tipología de Groenewoud (2001: 146) dada la naturaleza del sustrato geológico. La agrupación de tres hoyos de poste (UE 20096, 20097 y 20098) junto al extremo sur de la boca del pozo nos sugiere que éste debió estar cubierto por algún tipo de techumbre. Por causas desconocidas, tal vez su salinización con motivo de una sequía y de su proximidad al estuario del Bagradas, se clausuró.

${ }^{1}$ El profesor Doctor Joâo Luis Cardoso (com. pers.) de la Universidade Aberta de Lisboa ha estudiado la fauna de mamíferos. 


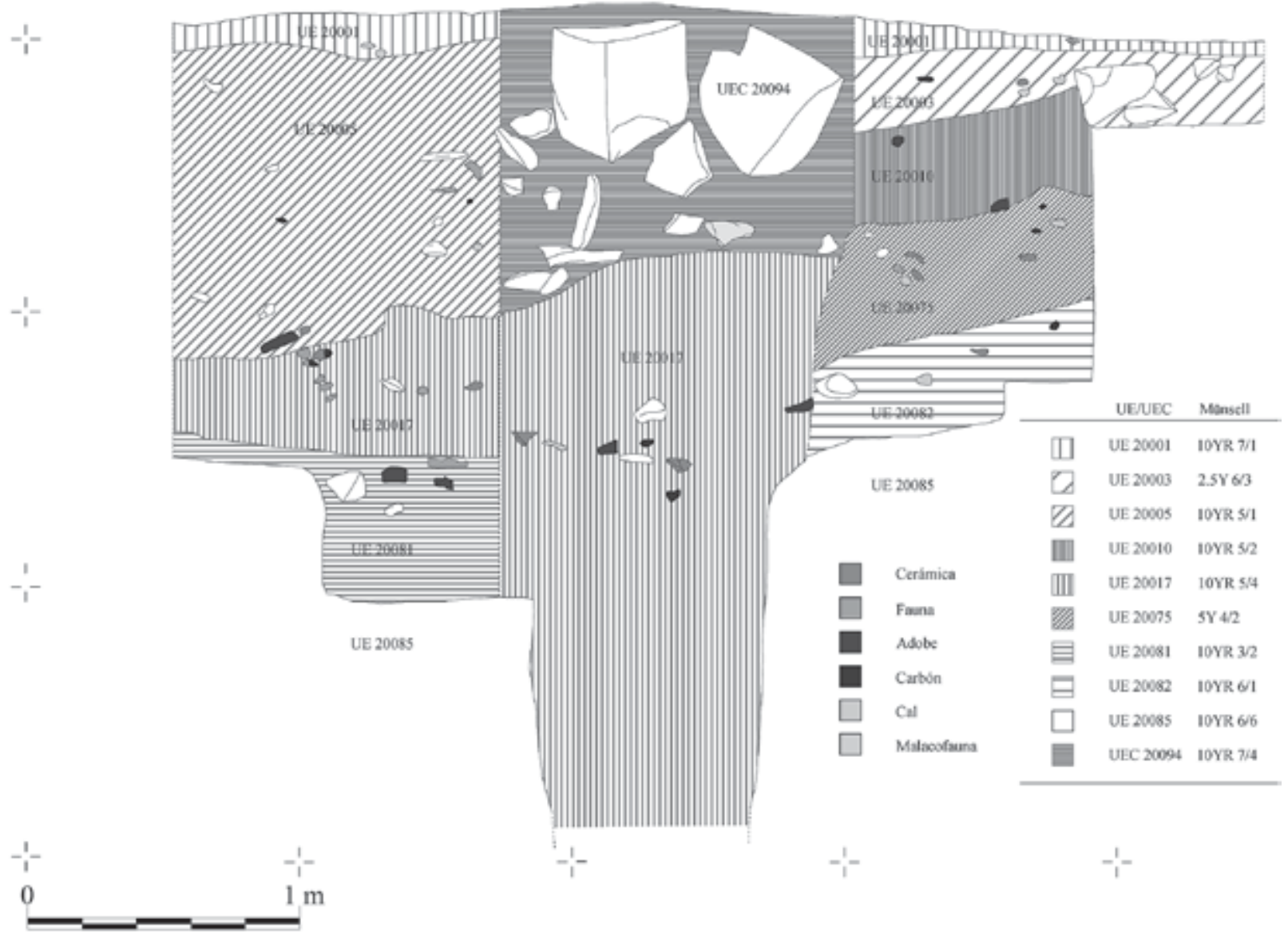

Fig. 5. Utica. Sección estratigráfica del corte 20 (campaña de 2012).

Tenemos ejemplos de clausuras rituales de pozos en asentamientos fenicios como Motya (Nigro y Spagnoli 2012; Nigro 2014; Spagnoli 2014) que nos recuerdan la clausura de Utica. Presentamos a continuación un avance al estudio de los materiales arqueológicos recuperados en el pozo 20017 de Utica efectuado con los materiales de la campaña de 2012.

\subsection{El conjunto cerámico del pozo 20017 de Utica}

El conjunto uticense de cerámicas fenicias del interior del pozo del corte 20 está formado principalmente por vajilla de mesa y de almacenamien- to, $\mathrm{y}$ en menor medida por cerámicas comunes y de cocina. Del poco más del millar de fragmentos cerámicos recuperados en la campaña de 2012, hemos calculado una distribución porcentual según la procedencia de las producciones cerámicas a partir del número mínimo de individuos (Fig. 8). Las cerámicas autóctonas libias modeladas a mano forman el conjunto mayoritario con un 56,78\%: el 37,97\% son producciones de tipología local y el 18,81\% imitaciones de formas fenicias. Las cerámicas fenicias, con un $26,95 \%$ componen el segundo, seguidas por las cerámicas importadas sardas con el 9,83\%, y las producciones griegas geométricas con el 4,24\% del total. Los vasos de producción villanoviana representan un $1,19 \%$ y los de producción tartésica apenas el 0,51\% del conjunto. Esta distribución, aun siendo represen- 


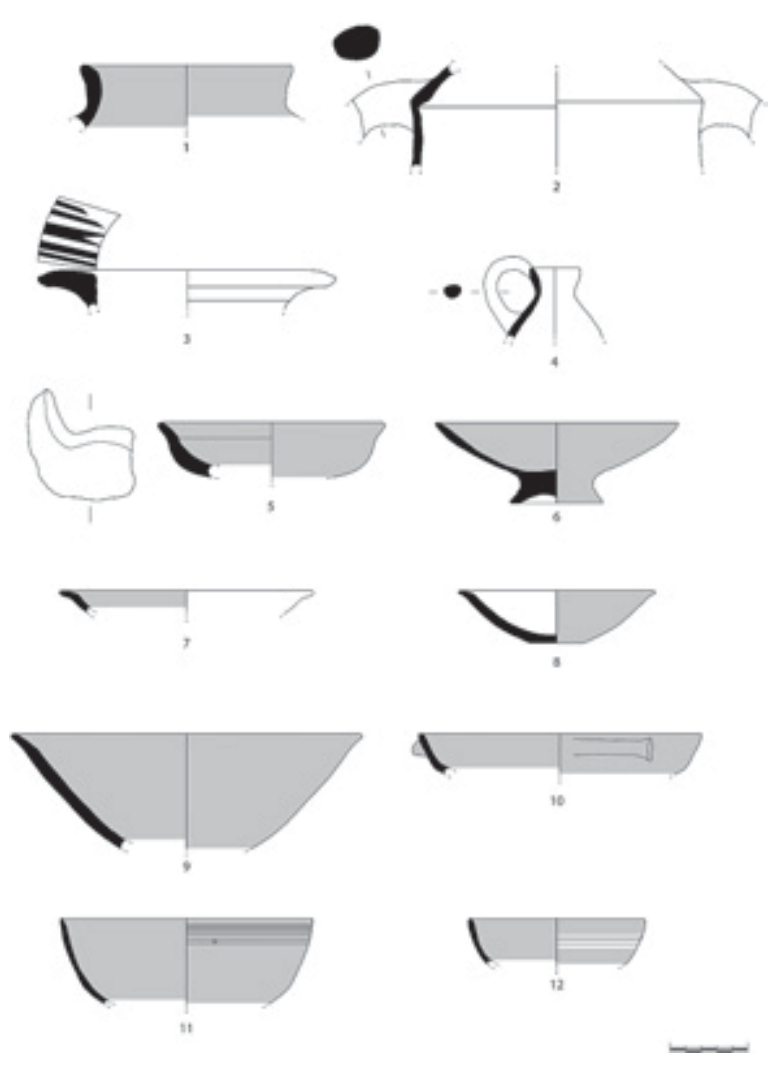

Fig. 6. Cerámicas fenicias del pozo 20017 de Utica.

tativa, deberá corregirse tras el estudio pormenorizado de las cerámicas de todas las campañas de excavación.

\subsubsection{Cerámica fenicia}

Entre las cerámicas de almacenamiento destacamos un fragmento de borde de ánfora decorada con engobe rojo (Fig. 6: 1) que por la forma del borde pertenecería al tipo 9 de Tiro, con paralelos tipológicos en los estratos IV, V-VII y VIII-IX (Bikai 1978: 45-46, pl. XIV: 13; XVIII: 12; XXI: 13). Bordes similares se localizan en Hazor VIII (Yadin et al. 1961: pl. CCXIII: 30) y en Occidente en el conjunto de calle Méndez Núñez de Huelva (González et al. 2004: 68-69, lám. XIII: 29-30). Un paralelo cercano al ejemplar uticense podría ser el ánfora con engobe rojo en toda la superficie, con borde exvasado y engrosado de Kuntillet Ajrud (Ayalon 1995:
165, fig. 13: 5). Otro fragmento de ánfora de almacenamiento (Fig. 6: 2) conserva el inicio del cuerpo de tendencia recta, la carena, parte del hombro y del asa. Al carecer de borde su clasificación se hace difícil, si bien está en la línea del tipo 1 de Sagona (1982: 73-75, fig. 1: 1) y encontramos paralelos en Hazor IX-X, IXa y en Hazor VII (Yadin et al. 1961: pl. CCXI: 1 y 2; CLXXVI: 13, CLXXX: 23). Un fragmento de tipología similar procede de las excavaciones tunecino-francesas de Utica, próximas al corte 20, si bien de contextos secundarios (Ben Jerbania 2013: 47, fig. 42: 12). Aparece también un fragmento de jarrito (Fig. 7: 4) del tipo juglet 3 de Tiro por su cuerpo ovoide, documentado casi desde el inicio de la secuencia hasta Tiro VI, con mayor presencia en Tiro XIII y Tiro X (Bikai 1978: 42, pl. XCIII, 3). Tiene paralelos en el estrato VIIb de Tell-el-Fâr'ah (Chambon 1984: 61-62, pl. 51: 20), en el estrato VA-IVB de Meggido (Finkelstein et al. 2000: 296, fig. 11.39: 9) y en el estrato III de Tell Abu Hawam (Herrera y Gómez 2004: 117, lám. XXVI: 225). Destacamos un fragmento de borde exvasado de crátera (Fig. 6: 3) con decoración de finas bandas verticales negras en su parte superior. Este tipo de decoración y la tipología del borde aparecen inicialmente en cráteras chipriotas del ChiproGeométrico III (Gjerstaad 1960: fig. 17). En la fase II de Tiro Al-Bass se registra en cráteras chipriotas, o de producción fenicia inspirada por aquéllas (Aubet y Núñez 2008: 76-80; Núñez 2014: 70-71, 75, fig. 13 d), así como en una tumba de la necrópolis de Qashmie (Chapman 1972: 147, 162, fig. 32: 214) o en Huelva (González et al. 2004: 51, lám. XLIX: 1a, 2a).

Por último, entre las cerámicas comunes, hay lucernas monocórnicas con engobe rojo (Fig. 6: 5), ampliamente extendidas en los conjuntos cerámicos orientales, lisas o decoradas con pintura o engobe rojo. En Tiro su aparición es significativa desde el estrato VIII en adelante donde el tipo 1, el más extendido, es especialmente abundante en los estratos V y IV (Bikai 1978: 18-20). Lucernas de este tipo se registran en los estratos IX a VI de Hazor sin engobe rojo, y engobadas en Kuntillet Ajrud (Ayalon 1995: 178, fig. 22: 3), en el estrato III de Tell Abu Hawam (Herrera y Gómez 2004: 104-105, 244, lám. XVII: 158), o en los VIIb, c y d de Tell-el-Fâr'ah (Chambon 1984: 68, pl. 59: $1,4,8-9)$. 

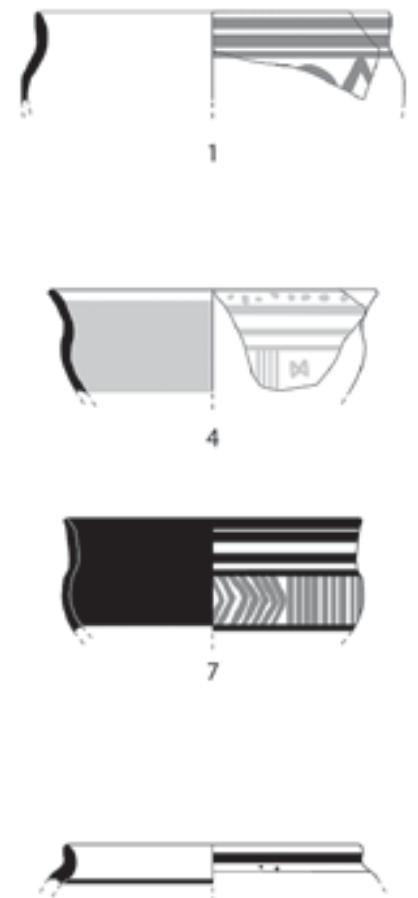

10

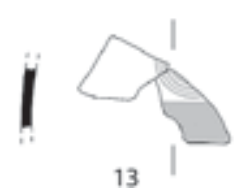

13

Fig. 7. Cerámicas griegas del pozo 20017 de Utica.

El grupo de vajilla de mesa está formado principalmente por platos y jarras de engobe rojo, platos de fine ware y algunos vasos menos habituales. Entre los platos de engobe rojo tenemos un borde (Fig. 6: 7) que recuerda al tipo 7 de Tiro, donde aparece desde el estrato VI y es más abundante en los estratos V y IV (Bikai 1978: 23). Encontramos un paralelo cercano en el estrato IVA de Meggido (Finkelstein et al. 2000: 301, fig. 11.43: 14). Otros platos documentados con engobe interior y exterior (Fig. 6: 9) o sólo exterior (Fig. 6: 8) podrían acercarse al tipo 9 de Tiro, presente en buena parte de su secuencia y abundante en Tiro VI-V (Bikai 1978: 21, 24), si bien nuestras piezas tienen el borde apuntado, sin estar engrosado. Hay formas muy parecidas, de tendencia abierta y perfil profundo, aunque sin engobe rojo en toda la superficie, en el estrato
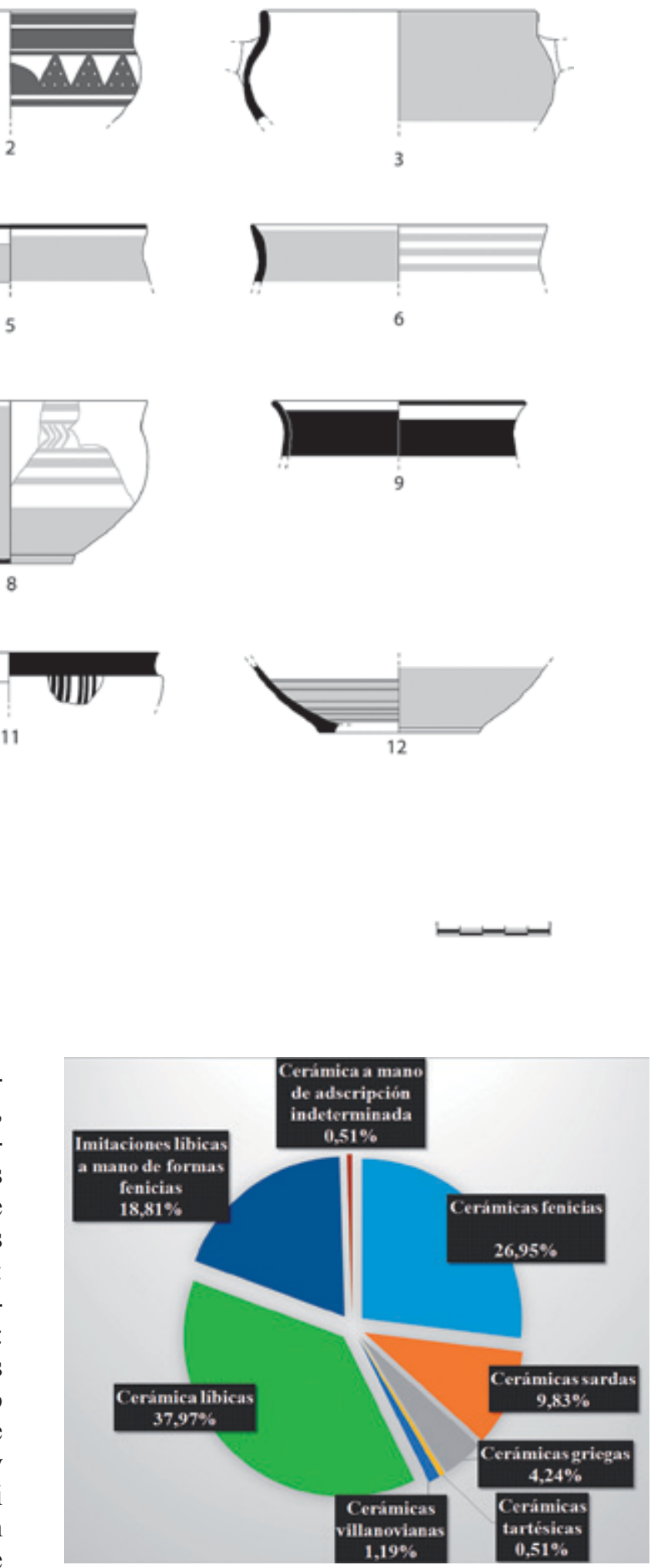

Fig. 8. Distribución de las producciones cerámicas documentadas en el pozo 20017 de Utica. 
VIId de de Tell-el-Fâr'ah (Chambon 1984: 66, pl. 57: 14, 16) o en los estratos X-IX (Yadin et al. 1958: pl. XLV: 9), IXa y VIII de Hazor (Yadin et al. 1961: pl. CLXXVIII: 1, 26, 28; pl. CCXIII: 25). También se documentan con barniz rojo en el estrato IVA de Meggido (Finkelstein et al. 2000: 301, fig. 11.43: 10)

Los platos de fine ware registrados en Utica (Fig. 6: 11 y 12) son adscribibles formalmente al tipo 8 de Tiro, presente desde el estrato XIII (Bikai 1978: pl. XXXI: 12; XIX: 2) y de manera más significativa en los estratos IX a VI, con mayor abundancia en este último (Bikai 1978: 26-27, 29). Sin embargo, los ejemplares tirios carecen de acanaladuras incisas bajo el borde, como los del estrato VIII de Hazor (Yadin et al. 1960: pl. LV: 10, 11, 28). En el estrato III de Tell Abu Hawam se constatan vasos iguales a los uticenses de la clase engobe rojo bruñido 3 (Herrera y Gómez 2004: 68-69, 232-233, lám. X: 90), así como en el conjunto de Huelva (González et al. 2004: 42, lám. XLVI: 20-22) y en el estrato VIId de Tell-el- Fâr'ah (Chambon 1984: 69, pl. 61: 23) sin engobe rojo.

Una de las formas menos corrientes en los conjuntos orientales es una copa con pie bajo de engobe rojo interior y exterior (Fig. 6: 6) que recuerda el chalice del estrato XVI de Tiro (Bikai 1978: pl. XVLIIA: 5). Un plato de engobe rojo, con pie más alto que el de Utica y perfil más anguloso, procede del estrato III de Tell Abu Hawam $\mathrm{y}$ ha sido interpretado como incensario (Herrera y Gómez 2004: 104, 246; lám. XIX: 171). Del mismo tipo es un cuenco con pedestal de Khirbet Silm (Chapman 1972: 170, fig. 28: 154) y otro más anguloso en el pie del estrato IVA de Meggido (Finkelstein et al. 2000: 301, fig. 11.43: $15)$. Es mucho más parecido a la copa uticense un chalice más tardío del estrato Ia de Hazor (Yadin et al. 1961: pl. CCLXXIII: 2).

Otra pieza particular registrada en Utica es un plato del tipo bar handled, con asa de barra o asa tubular (Fig. 6: 10), documentado en el Periodo II de Tiro-Al Bass (Núñez 2014: 76, fig. 9b), así como entre las formas del pottery period I de Samaria (Crowfoot et al. 1957: 99, fig. 1 Period I: 3). Esta forma se conoce también en el estrato VIId de Tell-el-Fâr'ah (Chambon 1984: 65, pl. 56: 4-6) y en los estratos IX a VI de Hazor con diferentes tamaños y bordes con un paralelo de la pieza uticense en el estrato VII (Yadin et al. 1961: pl. CLXXIII: 32).
En términos tipológicos y cronológicos, el conjunto de cerámica fenicia que hemos analizado podríamos situarlo, según las más recientes sistematizaciones de la cerámica fenicia oriental (Núñez 2010: fig. 1, 2014: fig. 1), en el Periodo II de Tiro Al Bass. Su final se data con anterioridad a finales del siglo IX a.C., coincidiendo con la primera mitad del horizonte de Salamis definido por Bikai (1983: 68-69) y con los estratos X/IX a VI de la estratigrafía de Tiro.

\subsubsection{Cerámicas griegas}

Entre las cerámicas del pozo del corte 20 destaca un conjunto de cerámicas griegas geométricas. Las más numerosos son los skyphoi, el vaso del servicio para beber más popular desde comienzos del Geométrico Medio (Coldstream 2008: 18). Con diferentes decoraciones, en su mayoría de procedencia eubea o de tipo eubeo, los ejemplares uticenses parecen situarse por sus formas y su repertorio decorativo en el horizonte del Geométrico Medio II. Los más numerosos son los bordes y fondos de skyphoi monócromos de influencia ática con barnices pardos y negros al interior y al exterior (Fig. 7: 12) o sólo al exterior (Fig. 7: 3). En Eretria los skyphoi monocromos más antiguos suelen ser globulares, lisos salvo las bandas de reserva al borde (Verdan et al. 2008: 72), como algunos ejemplares de Utica (Fig. 7: 3, 5). Otros fragmentos uticenses presentan bandas de reserva en el interior y en el exterior del borde (Fig. 7: 5-6, 9), como suele ser habitual en las copas eubeas del Geométrico Medio (Andrioménou 1985: 55-61, 69). Es una clase poco atestiguada en Occidente, concretamente en Pontecagnano, Cumas y Huelva (D'Agostino 1990: 80; Kourou 2005: 503).

Los skyphoi decorados con semicírculos colgantes de tradición protogeométrica son también producciones eubeas. Tenemos un fragmento de borde con barniz negro y hombro marcado (Fig. 7: 11) que, a pesar del mal estado de conservación, permite reconocer el arranque bajo el borde de siete semicírculos de pintura roja. Es muy parecido a los conocidos en Huelva y a un ejemplar de Veio (Descoudres y Kearsley 1983: fig. 43; González et al. 2004: 86-87) podría encuadrarse tanto en el tipo 5 como en el 6 de Kearsley por estar

Trab. Prehist., 73, N. ${ }^{\circ}$ 1, enero-junio 2016, pp. 68-89, ISSN: 0082-5638

doi: $10.3989 /$ tp.2016.12164 
incompleto (Kearsley 1989: 98-103). Asimismo, dos fragmentos de Utica parecen pertenecer a la parte inferior del cuerpo de un skyphos decorado al menos con cinco semicírculos colgantes y una banda barnizada inferior de delimitación (Fig. 7: 13), con un paralelo muy parecido en Calcis (Andrioménou 1985: 53, nº 12, fig. 8).

Entre las producciones de estilo aticizante hay dos skyphoi decorados con chevrons. En uno (Fig. 7: 7) están delimitados por barras verticales que ocupan la zona reservada entre las dos asas, como es común en los vasos del Geométrico Medio (Coldstream 2008: 25, pl. 4: c). El otro sólo conserva un fragmento de la parte alta del vaso con chevrons en la banda central reservada (Fig. 7: 8). Este motivo tiene su máximo desarrollo en el Geométrico Medio II ático, ocupando el lugar central de la decoración y fue rápida y ampliamente reproducido en las producciones eubeas contemporáneas (Coldstream 2008: 24, 165, 170; Verdan et al. 2008: 35, 75-76). En Occidente vasos con esta decoración del Geométrico Medio II están presentes en la Península Itálica, sobre todo en la necrópolis Pontecagnano, así como principalmente en Cumas y Veio (Boitani 2005; Kourou 2005). En la Península Ibérica, aunque no se conocen en Huelva, skyphoi con chevrons del Geométrico Medio se documentan en La Rebanadilla (Sánchez et al. 2012: 75, fig. 12).

Otros dos fragmentos de skyphoi de Utica (Fig. 7: 1-2) tienen un tipo de decoración no documentada hasta ahora en Occidente. Son triángulos seguidos de bandas semicirculares en el cuerpo, el segundo de los cuales está cuadriculado. Los crosshatched triangles aparecen ya en el Submicénico y en las decoraciones del Protogeométrico de Eubea (Andrioménou 1986: $\mathrm{n}^{\circ} 15$, fig. 16; $\mathrm{n}^{\circ}$ 16, fig. 17; $\mathrm{n}^{\mathrm{o}} 21$, fig. 23), el Peloponeso y Creta (Coldstream 1996: 342, 345, 352, 377) donde están muy extendidos, así como en el Geométrico Inicial del Dodecaneso (Coldstream 2008: 222, pl. 46 d, pl. 48 h; 266-267, pl. 58 b-c). Esta decoración continuó hasta el Geométrico Medio (Coldstream 1996: 354 y 2008: 268, pl. 59 a), si bien en diversas formas y más raramente en skyphoi, del que conocemos un ejemplar del Geométrico Medio II en Calcis (Andrioménou 1984: 64-65, $\mathrm{n}^{\mathrm{o}} 37$, fig. 20). Por último, la decoración con dots o puntos en el borde aparece en dos fragmentos uticenses (Fig. 7: 4, 10): el primero con interior monócromo, borde y cuerpo con bandas y líneas verticales en la parte central, formando una metopa en cuyo interior se dispone un hourglass. El segundo carece de cuerpo. Los puntos aparecen en el Geométrico Medio I, en particular en los bordes de los skyphoi, y las líneas de dots se extienden ya en el Geométrico Medio II (Coldstream 2008: 19, 24; Verdan et al. 2008: 74). En la Península Ibérica se conocen estos motivos en un fragmento de skyphos del Geométrico Medio II procedente de la fase IV de El Carambolo, superpuesta a la fase fundacional (Escacena et al. 2007: 16, fig. 14). El motivo de hourglass o clepsidra se extiende desde el Geométrico Medio II a comienzos del Geométrico Tardío por el Ática, Cícladas y Eubea (Gimatzidis 2010: 141).

\subsubsection{Cerámicas sardas}

Las cerámicas nurágicas sardas en Útica son principalmente recipientes vinculados con el consumo del vino, tanto las ánforas, que debían tener una capa de resina vegetal en su interior para impermeabilizarlas (Botto 2007: 16-19, 22), como pequeñas jarros o askoi. Por los análisis realizados sobre una brocca askoide del Nuraghe Bau Nuraxi di Triei, se han detectado en su interior trazas de vino (Sanges 2007), al igual que en otra brocchetta askoide del nuraghe Funtana di Ittireddu (Campus y Leonelli 2012: 159 n. 54), planteándose que servirían para sellar acuerdos entre marinos sardos y élites locales (Botto 2011: 43).

Las ánforas son quizás la forma más abundante en Utica, donde también se documentan en las excavaciones tunecino-francesas en contextos secundarios del sondeo I-3, con algunos tipos similares a los que presentamos (Ben Jerbania 2013: 25-30, 47, fig. 43). Cronológicamente las ánforas son menos definitorias porque los tipos se mantienen, al menos desde fines del siglo IX a.C. en que se datan en Sant'Imbenia (Oggiano 2000: 240), hasta el primer cuarto del siglo VII a.C. en Cartago. De la forma zentral-italische Amphoren, o ZitA 1-2 (Docter et al. 1997), denominadas después Nurágica 1-2 al ser identificadas en Sant'Imbenia, con desgrasantes de cuarzo y mica, que a veces tienen engobe rojo o marrón claro al exterior, tenemos varios ejemplares en el pozo del corte 20 (Fig. 9: 1-4), algunas con engobe (Fig. 9: 1). En España el conjunto más importante procede 

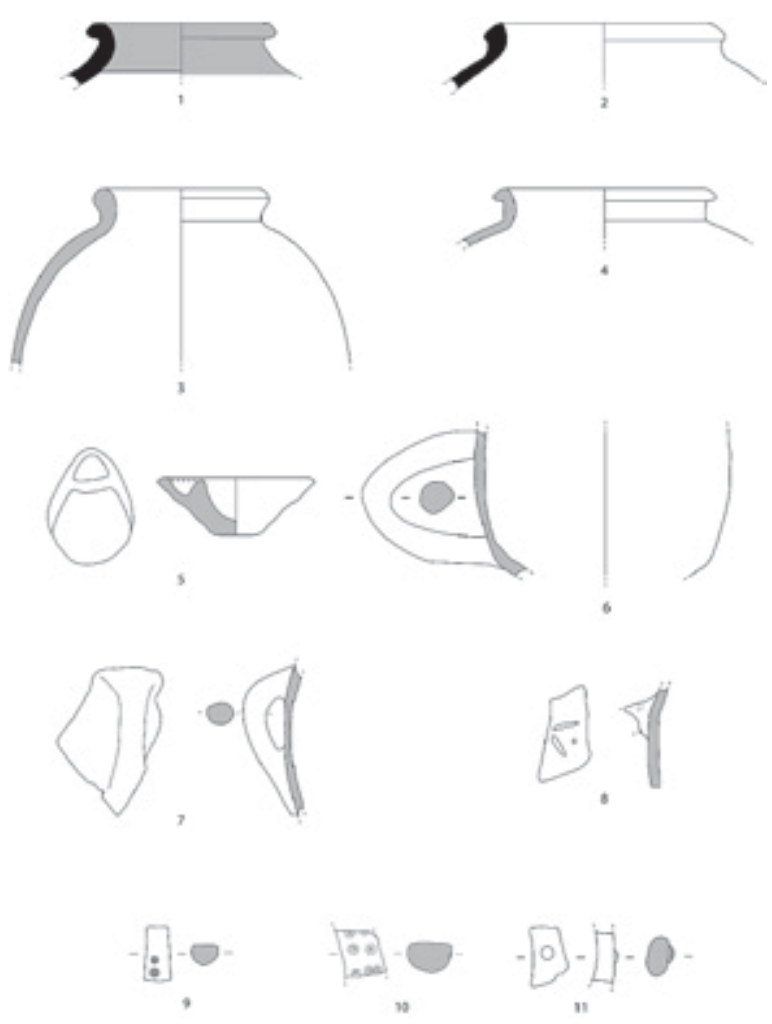

Fig. 9. Cerámicas nurágicas del pozo 20017 de Utica.

de Méndez Núñez-Plaza de las Monjas de Huelva. Se identificaron 9 ejemplares, algunos (González et al. 2004: 70-71, lám. XIV: 1-2) con similitudes con fragmentos uticenses (Fig. 9: 1-2). En Málaga las tenemos tanto en niveles arcaicos, en la fase III de La Rebanadilla (Sánchez et al. 2012: 71, 72 fig. 7:1-4) o en el Castillo de Doña Blanca en Cádiz (Ruiz Mata 1999: 305), como en contextos más recientes de Toscanos ${ }^{2}$ y Chorreras (Martín Córdoba et al. 2007: 30, fot. 16) (Fig. 9: 2-4). Encontramos en la cerámica nurágica lucernas con fondo plano que individualizan en un extremo un pequeño recipiente (Fig. 9: 5), aunque con una forma algo más ancha: el denominado vaso múltiple incluido entre las scodelle (Campus y Leonelli 2000: 613, 614, lám. 362: 1).

\footnotetext{
${ }^{2}$ Docter, R. F. 1997: Archaische Amphoren aus Karthago und Toscanos. Fundspektrum und Formentwicklung. Ein Beitrag zur phönizischen Wirtschaftsgeschichte. Dissertation. Faculteit der Letteren. Universiteit van Amsterdam, pp. 192-202.
}

Las grandes asas de cinta vertical a veces son sobreelevadas y aparecen en cuencos con base plana o attingitoi (Campus y Leonelli 2000: 209, 250 lám. 145: 8). En el ejemplar de Utica (Fig. 9: 6) el asa no supera la altura del borde, aunque está muy cerca de él, por lo que se encontraría entre los boccali a corpo arrotondato (Campus y Leonelli 2000: 379, 387, lám. 220:3), formas típicas del Bronzo Finale I (Campus et al. 2010: 63, fig. 1) desde los siglos XII-XI AC (Campus y Leonelli 2006: 388, 389, fig. 3: 18). Una pieza completa con un asa similar, pero con borde marcado divergente se ha descubierto en la fase III de La Rebanadilla en Málaga (Arancibia et al. 2011: 144, fig. 14; Campus y Leonelli 2000: 388, lám. 221: 5).

El asa de cinta vertical más fina en la parte superior y que se ensancha en la parte inferior, $a$ nastro stretto, es típico de recipientes nurágicos (Campus y Leonelli 2000: 626, 656, lám. 378: 1) (Fig. 9: 7). Las asas con decoración de trazos cortos incisos a veces los tienen también en el asa del askos (Fig. 9: 8) (Campus y Leonelli 2000: 396, 408, lám. 232: 3).

Al askos o brocca askoide, que probablemente servía para contener una bebida más densa y de mayor graduación, al estilo del actual licor sardo de mirto rosso (Myrtus communis), corresponde el asa más típica con círculos concéntricos impresos en línea vertical (Campus y Leonelli 2000: 623, lám. 373: 4, 7 y 11), del que tenemos un fragmento en Utica (Fig. 9: 9). Esta forma está en Huelva, en Méndez Núñez (González et al. 2004: 101, lám. 21: 4, 60: 4) y en el yacimiento PP8 (Fundoni 2009: 17, lám. 3: 1), así como en El Carambolo de Sevilla (Carriazo 1973: 536, fig. 384; Torres 2004: 46, fig. 1) y la calle Cánovas del Castillo de Cádiz (Córdoba y Ruiz Mata 2005: 1300, 1303, 1310, fig. 20). En el Mediterráneo Oriental esta decoración se documenta en el asa de la broccheta askoide de la tumba 2 de Khaliale Tekke, en Creta (Vagnetti 1989: 356-359), que comienza a usarse en el Protogeométrico. Es una forma que se pensaba que aparecía en la última fase del Bronzo Finale, paralelamente al apogeo de la producción de bronces sardos (Lo Schiavo 2005: 112), aunque sus orígenes se remontan al Bronzo Finale I (Campus et al. 2010: 63, 72, fig. 1) desde los siglos XII-XI a.C. (Campus y Leonelli 2006: 388-389, fig. 3: 20), continuando en

Trab. Prehist., 73, N. ${ }^{\circ}$ 1, enero-junio 2016, pp. 68-89, ISSN: 0082-5638 doi: $10.3989 /$ tp. 2016.12164 
el Bronzo Finale II, entre los siglos X-IX a.C. (Campus y Leonelli 2006: 390-391, fig. 3a/10).

En otro fragmento de Utica estos círculos concéntricos forman líneas verticales de círculos concéntricos impresos (Fig. 10: 10), a veces con cierta irregularidad, como en ejemplos sardos (Campus y Leonelli 2000: 623-624, 651-652, lám. 373: 8, 13, 374: 8). En la Península Ibérica se conoce en la fase III de La Rebanadilla en Málaga (Sánchez et al. 2012: 73, fig. 9: 4). También la encontramos en fechas más tardías en Cartago, en el nivel IIIa1 de la casa 2 de las campañas de la Universidad de Hamburgo (Kollund 1992-93: 211, fig. 5). Finalmente, en Utica tenemos fragmentos más excepcionales (Fig. 9: 11) de asas con pequeños botones realzados y alineados verticalmente o pastiglie. Aparecen tanto en asas como, más frecuentemente, en el cuerpo del recipiente (Campus y Leonelli 2000: 641-642, 690, lám. 412).

\subsubsection{La cerámica villanoviana}

Entre los materiales importados que presentamos en este artículo, la cerámica villanoviana está relativamente bien representada en el pozo 20017 y se conocen algunos fragmentos uticenses de las excavaciones tunecino-francesas en contextos secundarios del sondeo I-3 (Ben Jerbania 2013: 25-30, 48-49, fig. 44). Como la inmensa mayoría del material recuperado en este depósito, la cerámica villanoviana corresponde a vasos destinados al servicio y consumo de alimentos. Contamos con dos copas de la característica dark polished ware con una y dos asas (Fig. 10: 2-3). Relacionamos las dos piezas restantes (Fig. 10: 4-5), a pesar del escaso tamaño conservado, con formas cerradas como jarras o botellas por el acabado de la pieza (ordinary ware) y la decoración (Hencken 1968: 26).

La primera copa (Fig. 10: 2) presenta una decoración tipo A 166 (Gastaldi 1998: 20 y 22) o 17 ss 36 (Hencken 1968: 30) de triángulos contiguos con vértices opuestos, elaborada con la técnica de la ruedecilla, que se data en la segunda mitad del siglo IX a.C. (Gastaldi 1998: 9). Los paralelos más representativos están en las fases IA y IB de la necrópolis de Pontecagnano (Salerno) (Gastaldi 1998: 65-149), en numerosas tumbas

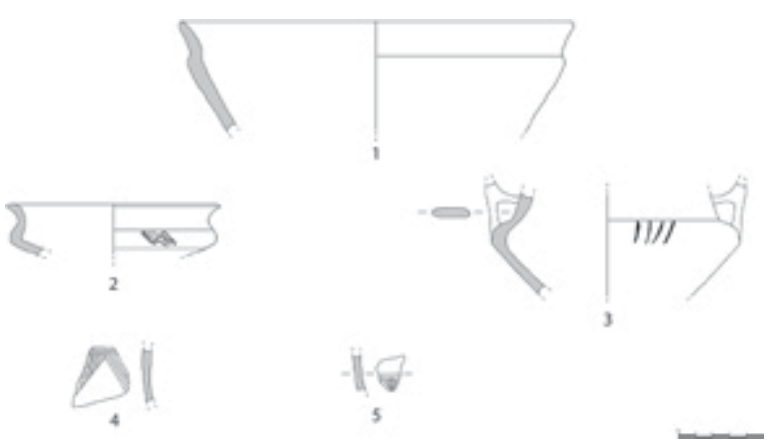

Fig. 10. Cerámicas villanovianas y tartesias del pozo 20017 de Utica.

de las necrópolis de Selciatello (Hencken 1968: 58 y 66), Selciatello Sopra (Hencken 1968: 92165), Poggio Impiccato (Hencken 1968: 58, 120 y 124) y Monterozzi (Hencken 1968: 185 y 215) de Tarquinia (Viterbo). También aparecen en las cabañas A y B de Luni, en el área D oeste de San Giovenale (Pacciarelli 2006: 38-41), en los niveles IIA1 y IIA2 de la necrópolis de Osteria dell'Osa (Roma) (Pacciarelli 2006: 59-62) y en las áreas 20D y 32A del asentamiento villanoviano en Vulci (Viterbo) (Pacciarelli 2006: 144 y 148). En el Sur de Italia se documentan en las necrópolis de La Rota, Canale-Ianchina, Patariti y Scorciabove (Locri, Calabria) (Pacciarelli 2006: 48-52).

La segunda copa (Fig. 10: 3), por su parte, presenta la decoración tipo A 090 (Gastaldi 1998: 19-20) conformada por trazos oblicuos y paralelos, incisos mediante una única punta, técnica utilizada durante todo el siglo IX y la primera mitad del VIII a.C. (Guidi 1980: 11; Gastaldi 1998: 10). Entre los paralelos, destacamos la presencia de este tipo de copa en las fases IA y IB de la necrópolis de Pontecagnano (Gastaldi 1998: 65-149), en diversas tumbas de las necrópolis de Selciatello Sopra (Hencken 1968: 71-165), Poggio Impiccato (Hencken 1968: 120, 155 y 176) y Monterozzi (Tarquinia, Viterbo) (Hencken 1968: 209 y 215), en la necrópolis del Pantanaccio (Veio) (Pacciare1li 2006: 160-163), en las cabañas A y B de Luni (Pacciarelli 2006: 38-41), en la necrópolis de La Rota (Pacciarelli 2006: 48 y 50-51), en los niveles 1A/B y C de Torre Galli (Vibo Valentia, Calabria) (Pacciarelli 2006: 48-49) y en Torre Chiaruccia (Roma) (Pacciarelli 2006: 172-173).

Las dos jarras (Fig. 10: 4-5) se decoran con peine de 3 y 4 puntas respectivamente. El pe- 
ríodo generalizado de uso de la técnica finalizó a mediados del siglo IX a.C. (Guidi 1980: 14; Gastaldi 1998: 9). El motivo decorativo de la primera jarra, tipo A 140 (Gastaldi 1998: 20-21) o 21 ss 203 (Hencken 1968: 33) son los triángulos contiguos, mientras la segunda combina círculos concéntricos impresos del tipo A 030 (Gastaldi 1998: 19-21) y motivos lineales de difícil adscripción. De la decoración de la primera jarra (Fig. 10: 4) encontramos paralelos también en las fases IA y IB de la necrópolis de Pontecagnano (Gastaldi 1998: 65-149), en la necrópolis de Vulci (Pacciarelli 2006: 163), en Torre Chiaruccia (Pacciarelli 2006: 172-173), en la tumba 78 de la necrópolis de Impiccato (Hencken 1968: 156), en la tumba 2 del Poggio della Pozza (Allumiere, Roma) (Pacciarelli 2006: 42-43) y en el estrato 7 de Monterovello (Viterbo) (Pacciarelli 2006: 4244). Encontramos paralelos del fragmento decorado de la segunda jarra (Fig. 10: 5) en las mismas fases IA y IB de la necrópolis de Pontecagnano (Gastaldi 1998: 65-149), en las áreas 20D, 27A y 34 del asentamiento villanoviano de Vulci (Pacciarelli 2006: $144-145$ y 151) y en el estrato 7 de Monterovello (Pacciarelli 2006: 42-44).

\subsubsection{Las cerámicas tartésicas}

Una cazuela carenada a mano del Bronce Final del tipo AIa de Ruiz Mata (1995: 286-287, fig. 2-3) (Fig. 10: 1) es un ejemplo de las importaciones ibéricas. Las de tipo Cabezo de San Pedro suelen diferenciarse de los tipos del Bajo Guadalquivir por tener un borde más alargado $\mathrm{y}$ carena más marcada. En la pieza de Utica, la carena algo más suave, el bruñido al interior, el tipo de pasta y la coloración, más castaña clara frente a los tonos negros o grisáceos oscuros de Huelva, apuntan a una procedencia del Bajo Guadalquivir (Ruiz Mata 1995: 267-268). En esta área ya se conocían estas cazuelas en los niveles IV y III de la denominada Cabaña de El Carambolo, con algún ejemplo idéntico al uticense (Carriazo 1973: 534, fig. 382). Otro borde igual procede de las excavaciones recientes, en la unidad $15 \mathrm{c}$ correspondiente al nivel IV de Carriazo (Fernández y Rodríguez 2007: 153 fig. 55/1, Car-15a-5) o en la UE-1064, inicio de la fase IV de las nuevas excavaciones de El Carambolo (Escacena et al.
2007: 18, fig. 13: CAR-1064-35). Su pervivencia asociada a cerámicas fenicias, otras con decoración de tipo Carambolo, ánforas T-10 y platos de engobe rojo (Gómez Toscano et al. 2009: 621, fig. 5: 1) se puede observar en un fondo de cabaña de Huelva, sector Vista Alegre-Universidad. En Utica también hay en contextos secundarios del sondeo I-3 un fragmento de un borde divergente de cazuela con triángulo exterior grabado (Ben Jerbania 2013: 25-30, 49, fig. 22). La decoración, bien representada en el Bajo Guadalquivir (Casado 2011: 100, fig. 2: CAR-2199-102), amplía el repertorio de importaciones ibéricas en el Norte de África, pues ya se habían documentado en contextos antiguos de Cartago (Mansel 2011).

\subsubsection{Las cerámicas libias}

Las cerámicas a mano autóctonas son de tipología local o imitan formas fenicias. Sus paralelos están en estratos del periodo Numídico Antiguo de Althiburos, con dataciones de $\mathrm{C} 14$ de los siglos X-IX cal AC (Ramón y Maraui 2011: 154, n. 26) y de Cartago, fechados en el siglo VIII a.C. Entre la primera clase destaca una olla de perfil en "s" con cuerpo globular, borde marcado y asas paralelas al borde y verticales (Fig. 11: 1). Una forma muy similar de Cartago, en lugar de asas presenta mamelones (Mansel 1999: 237, Abb. 3, 26). El fragmento de borde de olla de la misma tipología (Fig. 11:3) encuentra un paralelo contemporáneo en la fase más antigua de Althiburos (Ramon y Maraui 2011: 389, 290432: 20), un tipo presente también entre las formas más corrientes de la cerámica autóctona de Cartago (Mansel 1999: 236, Abb. 3, 17). En este asentamiento un fragmento de vasija horno con borde marcado, bajo el que se disponen digitaciones, es similar a uno uticense (Fig. 11: 2). También de la fase más antigua de Althiburos (Ramon y Maraui 2011: 388, 290428: 1) procede un cuenco profundo idéntico al ejemplar uticense (Fig. 11: 4). Por último señalaremos la presencia de cuencos lenticulares con mamelones en el borde (Fig. 11: 5).

Se imitan las lucernas fenicias monocórnicas (Fig. 11: 7). En Cartago hay también lucernas de imitación más tardías, en algún caso de tres picos (Mansel 2007: 436, Abb. 229: 2709-2711). Además hay platos con decoración a barniz rojo

Trab. Prehist., 73, N. ${ }^{\circ}$ 1, enero-junio 2016, pp. 68-89, ISSN: 0082-5638

doi: $10.3989 /$ tp.2016.12164 


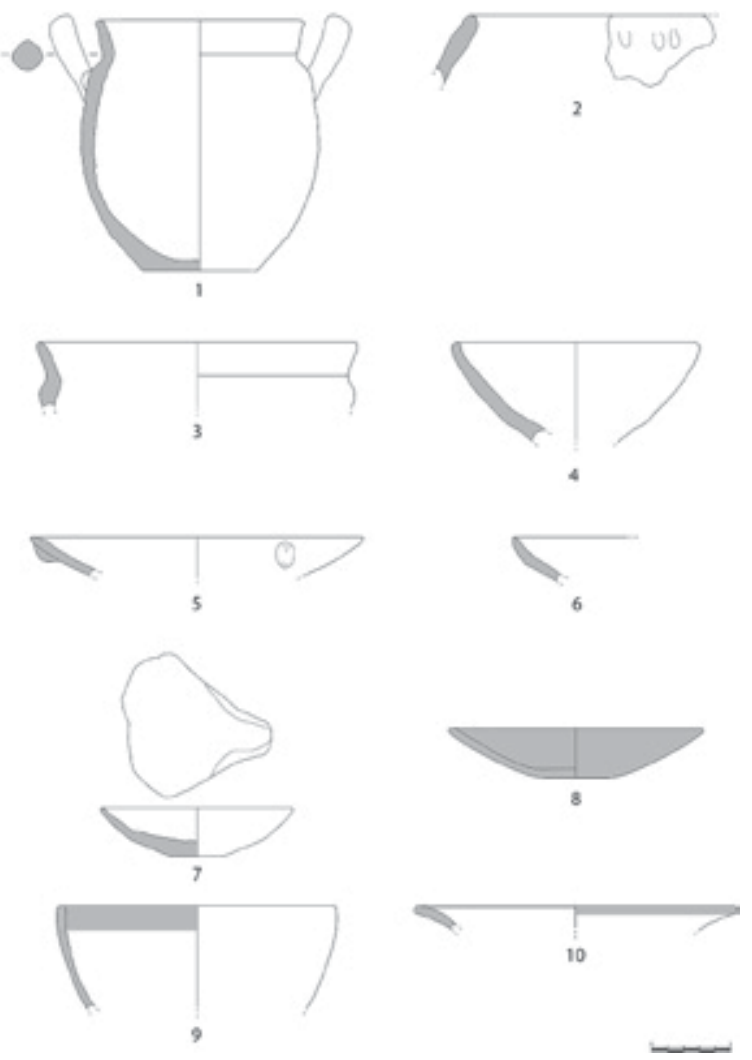

Fig. 11. Cerámicas libias del pozo 20017 de Utica.

que imitan platos fenicios del tipo 10 de Tiro (Fig. 11: 8), similares a los de Cartago (Mansel 2007: 437, Abb. 230, 2712) con borde o borde e interior engobados. Otros platos uticenses presentan el borde decorado y ligeramente vuelto (Fig. 11:10) como los del estrato VII d de Tel-el Far'ah (Chambon 1984: pl. 57, 22) y un borde sin decoración imita el tipo 8 de los platos tirios (Fig. 11: 6; Bikai 1978: 21, 23-24). Por último, un cuenco profundo (Fig. 11:9) podría seguir una tipología local documentada en Cartago (Mansel 1999: 237, Abb. 4, 38), aunque el borde interior decorado en rojo podría ser por influencia fenicia.

\section{LAS DATACIONES DE C14 DEL POZO 20017}

La serie de Utica (Tab. 1), obtenida sobre semillas del relleno del pozo UE 20017 del corte 20, comprende tres dataciones muy homogéneas:
CNA-2400 2790 \pm 35 B.P. 1000 [966-921] $833 \mathrm{cal}$ AC, CNA-2402 2765 \pm 35 B.P. 1000 [903] $828 \mathrm{cal}$ AC y CNA-2403 2795 \pm 35 B.P. 1013 [967-923] 834 cal AC. Su oscilación máxima está en 1013828 cal AC en Intcal98 o 1025-832 AC en Intcal13, es decir hay un $95 \%$ de probabilidad de que la fecha sea entre fines del siglo XI cal AC a fines del siglo IX cal AC en la probabilidad mediana de la distribución de la probabilidad, si bien los puntos de intercepción en la curva de calibración apuntan al último cuarto del siglo $X$ cal AC, 925-900 cal AC. ${ }^{3}$ Las dos fechas procedentes de la fase IV de La Rebanadilla (Sánchez et al. 2012: 69, tab. 2), Beta-264.171 2810 \pm 40 B.P. 1049 [971-936] 835 cal AC y Beta-264.170 $2780 \pm 40$ B.P. 1000 [917] 829 cal AC (Tab. 1), 1049-829 cal AC con un $95 \%$ de probabilidad, se sitúan entre fines del siglo XI cal AC a fines del siglo IX cal AC. Los puntos de intercepción en la curva de calibración se sitúan entre 935-900 cal AC, de forma contemporánea al relleno del pozo 20017 de Utica.

La serie onubense de Méndez Núñez-Plaza de las Monjas (Nijboer y van der Plicht 2006: 32, tab. 1; 33, tab. 2) es también comparable con la de Utica (Tab. 1), a pesar de que no se trata de un contexto primario que, como señala Gilboa (2011: 321), puede incluir varios niveles diferentes. Estas dataciones también se mueven en una banda cronológica similar, ligeramente más reciente, GrN29.512998 [916] 834 cal AC, GrN-29.511969 [898] 828 cal AC, y GrN-29.513968 [896-845] $827,998-827$ cal AC, con un $95 \%$ de probabilidad entre inicios del siglo $\mathrm{X}$ al tercer cuarto del siglo IX cal AC, y los puntos de intercepción en la curva de calibración señalan un 915-845 cal AC.

De la fase más antigua del santuario de El Carambolo (Camas, Sevilla), o Carambolo V, en concreto de la habitación A-45, procede una datación radiocarbónica, Ua-24401 2770 \pm 50 B.P. 1016 [904] 814 cal AC (Tab. 1), recogida de una fina capa de herbáceas carbonizadas probablemente en la preparación del terreno para la construcción. Dicha capa continuaba bajo el muro de

\footnotetext{
${ }^{3}$ Se contrastan las curvas Intcal13 con Intcal98 (Tab. 1). La segunda puede mejorar a Intcal04 (Reimer et al. 2004) porque ésta suaviza los picos de la curva de calibración prolongando sólo ligeramente de 24.000 hasta 26.000 BP. Intcal09 (Reimer et al. 2009) básicamente supone la extensión de la curva de calibración de $26.000 \mathrm{BP}$ hasta $50.000 \mathrm{BP}$, recientemente refinada en Intcal13 (Reimer et al. 2013).
} 


\begin{tabular}{|c|c|c|c|c|c|c|c|c|}
\hline Yacimiento & Localización & B.P. & \pm & B.C. & $\begin{array}{l}\text { Máx. } \\
\text { CAL }\end{array}$ & CAL B.C. & $\begin{array}{l}\text { Min. } \\
\text { CAL }\end{array}$ & $\begin{array}{l}\mathrm{n}^{0} \text { Lab. \& } \\
\text { Material }\end{array}$ \\
\hline $\begin{array}{l}\text { Utica, corte 20, UE } \\
20017,-2.77-2.67 \mathrm{~m} .\end{array}$ & Túnez & 2795 & 35 & 845 a.C. & $\begin{array}{l}1025 \\
1013\end{array}$ & $\begin{array}{c}981-908 \\
967 \\
963 \\
923 \text { AC }\end{array}$ & $\begin{array}{l}842 \\
834\end{array}$ & $\begin{array}{l}\text { CNA-2403- } \\
\text { AMS/S }\end{array}$ \\
\hline $\begin{array}{l}\text { Utica, corte 20, UE } \\
20017,-3.17-3.07 \mathrm{~m} .\end{array}$ & Túnez & 2765 & 35 & 815 a.C. & $\begin{array}{c}998 \\
1000\end{array}$ & $903 \mathrm{AC}$ & $\begin{array}{l}832 \\
828\end{array}$ & $\begin{array}{l}\text { CNA-2402- } \\
\text { AMS/S }\end{array}$ \\
\hline $\begin{array}{l}\text { Utica, corte 20, UE } \\
20017,-3.36-3.32 \mathrm{~m} .\end{array}$ & Túnez & 2790 & 35 & 840 a.C. & $\begin{array}{l}1016 \\
1000\end{array}$ & $\begin{array}{c}981-903 \\
966 \\
964 \\
921 \mathrm{AC} \\
\end{array}$ & $\begin{array}{l}840 \\
833\end{array}$ & $\begin{array}{l}\text { CNA-2400- } \\
\text { AMS/S }\end{array}$ \\
\hline La Rebanadilla fase IV & Málaga & 2810 & 40 & 860 a.C. & $\begin{array}{l}1057 \\
1049\end{array}$ & $\begin{array}{c}971 \mathrm{AC} \\
959 \\
936\end{array}$ & $\begin{array}{l}843 \\
835\end{array}$ & $\begin{array}{l}\text { Beta-AMS- } \\
264.171 / \mathrm{C}\end{array}$ \\
\hline La Rebanadilla fase IV & Málaga & 2780 & 40 & 830 a.C. & $\begin{array}{l}1016 \\
1000\end{array}$ & $917 \mathrm{AC}$ & $\begin{array}{l}830 \\
829\end{array}$ & $\begin{array}{l}\text { Beta- AMS- } \\
264.170 / \mathrm{C}\end{array}$ \\
\hline La Rebanadilla fase I & Málaga & 2700 & 40 & 750 a.C. & $\begin{array}{l}919 \\
967\end{array}$ & $832 \mathrm{AC}$ & $\begin{array}{l}801 \\
801\end{array}$ & $\begin{array}{l}\text { Beta-AMS- } \\
264.173 / \mathrm{C}\end{array}$ \\
\hline La Rebanadilla fase I & Málaga & 2610 & 40 & 660 a.C. & $\begin{array}{l}893 \\
895\end{array}$ & $\begin{array}{l}846-750 \\
806 \text { AC }\end{array}$ & $\begin{array}{l}590 \\
790\end{array}$ & $\begin{array}{l}\text { Beta-AMS- } \\
264.172 / \mathrm{C}\end{array}$ \\
\hline $\begin{array}{l}\text { La Rebanadilla, San } \\
\text { Isidro, tumba } 9 \text {, fase II }\end{array}$ & Málaga & 2660 & 60 & 710 a.C. & $\begin{array}{l}975 \\
919\end{array}$ & $\begin{array}{l}946-755 \\
812 \mathrm{AC}\end{array}$ & $\begin{array}{l}596 \\
765\end{array}$ & $\begin{array}{l}\text { Beta-AMS- } \\
264.174 / \mathrm{M}\end{array}$ \\
\hline $\begin{array}{l}\text { Méndez Núñez-Plaza } \\
\text { de las Monjas, Huelva }\end{array}$ & Huelva & 2775 & 25 & 825 a.C. & $\begin{array}{l}996 \\
998 \\
\end{array}$ & $916 \mathrm{AC}$ & $\begin{array}{l}845 \\
834 \\
\end{array}$ & $\begin{array}{c}\text { GrN-29.512/H } \\
\text { bos taurus }\end{array}$ \\
\hline $\begin{array}{l}\text { Méndez Núñez-Plaza } \\
\text { de las Monjas, Huelva }\end{array}$ & Huelva & 2745 & 25 & 795 a.C. & $\begin{array}{l}969 \\
969\end{array}$ & $\begin{array}{l}934-826 \\
898 \mathrm{AC}\end{array}$ & $\begin{array}{l}826 \\
828\end{array}$ & $\begin{array}{c}\mathrm{GrN}-29.511 / \mathrm{H} \\
\text { bos }\end{array}$ \\
\hline $\begin{array}{l}\text { Méndez Núñez-Plaza } \\
\text { de las Monjas, Huelva }\end{array}$ & Huelva & 2740 & 25 & 790 a.C. & $\begin{array}{l}966 \\
968\end{array}$ & $\begin{array}{c}930-823 \\
896 \mathrm{AC} \\
875 \\
862 \\
847 \\
845\end{array}$ & $\begin{array}{l}823 \\
827\end{array}$ & $\begin{array}{c}\text { GrN-29.513/H } \\
\text { bos }\end{array}$ \\
\hline $\begin{array}{l}\text { El Carambolo, fase V, } \\
\text { estancia A-45 }\end{array}$ & Camas, Sevilla & 2770 & 50 & 820 a.C. & $\begin{array}{l}1029 \\
1016\end{array}$ & $\begin{array}{l}944-843 \\
904 \mathrm{AC}\end{array}$ & $\begin{array}{l}813 \\
814 \\
\end{array}$ & Ua-24401/C \\
\hline $\begin{array}{l}\text { Alcorrín, fortificación } \\
\text { interior, corte } C \text {, muro }\end{array}$ & Manilva, Málaga & 2674 & 43 & 724 a.C. & $\begin{array}{l}907 \\
903\end{array}$ & $\begin{array}{c}847-801 \\
825\end{array}$ & $\begin{array}{l}794 \\
795 \\
\end{array}$ & Erl-11.553/C \\
\hline $\begin{array}{l}\text { Alcorrín, fortificación } \\
\text { interior, corte } \mathrm{C} \text {, foso }\end{array}$ & Manilva, Málaga & 2711 & 42 & 761 a.C. & $\begin{array}{l}968 \\
968 \\
\end{array}$ & $\begin{array}{l}932-801 \\
832 \mathrm{AC}\end{array}$ & $\begin{array}{l}801 \\
801\end{array}$ & Erl-11.550/C \\
\hline $\begin{array}{l}\text { Alcorrín, fortificación } \\
\text { interior, corte } \mathrm{C} \text {, foso }\end{array}$ & Manilva, Málaga & 2684 & 42 & 734 a.C. & $\begin{array}{l}911 \\
915\end{array}$ & $\begin{array}{l}850-804 \\
827 \mathrm{AC}\end{array}$ & $\begin{array}{l}797 \\
797\end{array}$ & Erl-11.552/C \\
\hline $\begin{array}{l}\text { Alcorrín, fortificación } \\
\text { exterior, sondeo } 1 \text {, UE } \\
17\end{array}$ & Manilva, Málaga & 2635 & 42 & 685 a.C. & $\begin{array}{l}895 \\
890\end{array}$ & $\begin{array}{l}832-791 \\
803 \mathrm{AC}\end{array}$ & $\begin{array}{l}772 \\
785\end{array}$ & $\begin{array}{c}\text { Erl-11.562/H } \\
\text { diente Sus } \\
\text { scrofa }\end{array}$ \\
\hline $\begin{array}{l}\text { Alcorrín, fortificación } \\
\text { exterior, sondeo 1, UE } \\
13\end{array}$ & Manilva, Málaga & 2676 & 42 & 726 a.C. & $\begin{array}{l}906 \\
903\end{array}$ & $\begin{array}{l}847-802 \\
826 \mathrm{AC}\end{array}$ & $\begin{array}{l}795 \\
796\end{array}$ & $\begin{array}{c}\text { Erl-11.560/H } \\
\text { ovicáprido }\end{array}$ \\
\hline
\end{tabular}

Tab. 1 [1]. Dataciones más antiguas de la presencia fenicia en Túnez y la Península Ibérica. Tipos de muestras: C: Carbón (Charcoal). H: Hueso (Bone). S: Semillas (Seeds). Fuentes: Arancibia et al. (2011: 137, tab. 1), Fernández Flores y Rodríguez Azogue (2007: 103-104), Marzoli et al. (2010: 174-175, tabs. 1-3), Nijboer y van der Plicht (2006: 32, tab. 1, 33, tab. 2), Sánchez et al. (2012: 69-70, fig. 2-4 y com. pers.). Curva de calibración intcal13, Calib v. 7.0.3. según Reimer et al. (2013) comparada con curva de calibración Intcal98, Calib v. 4.2 según Stuiver et al. (1998). 


\begin{tabular}{|c|c|c|c|c|c|c|c|c|}
\hline Yacimiento & Localización & B.P. & \pm & B.C. & $\begin{array}{l}\text { Máx. } \\
\text { CAL }\end{array}$ & CAL B.C. & $\begin{array}{l}\text { Min. } \\
\text { CAL }\end{array}$ & $\begin{array}{c}\mathbf{n}^{0} \text { Lab. \& } \\
\text { Material }\end{array}$ \\
\hline $\begin{array}{l}\text { Alcorrín, fortificación } \\
\text { exterior, sondeo } 1, \mathrm{UE} \\
12\end{array}$ & Manilva, Málaga & 2554 & 42 & 604 a.C. & $\begin{array}{l}808 \\
804\end{array}$ & $787 \mathrm{AC}$ & $\begin{array}{l}542 \\
540\end{array}$ & $\begin{array}{c}\text { Erl-11.559/H } \\
\text { diente } \\
\text { ovicáprido }\end{array}$ \\
\hline Cartago & Túnez & 2710 & 30 & 760 a.C. & $\begin{array}{l}909 \\
917\end{array}$ & $832 \mathrm{AC}$ & $\begin{array}{l}809 \\
804\end{array}$ & $\begin{array}{c}\mathrm{GrN}-26.091 / \mathrm{H} \\
\text { bos }\end{array}$ \\
\hline Cartago & Túnez & 2660 & 30 & 710 a.C. & $\begin{array}{l}895 \\
891\end{array}$ & $\begin{array}{l}851-795 \\
812 \text { AC }\end{array}$ & $\begin{array}{l}795 \\
797\end{array}$ & $\begin{array}{c}\mathrm{GrN}-26.094 / \mathrm{H} \\
\text { bos }\end{array}$ \\
\hline Cartago & Túnez & 2650 & 30 & 700 a.C. & $\begin{array}{l}894 \\
886\end{array}$ & $\begin{array}{l}849-791 \\
806 \text { AC }\end{array}$ & $\begin{array}{l}791 \\
795 \\
\end{array}$ & $\begin{array}{c}\mathrm{GrN}-26.090 / \mathrm{H} \\
\text { bos }\end{array}$ \\
\hline Cartago & Túnez & 2640 & 50 & 690 a.C. & $\begin{array}{l}917 \\
898\end{array}$ & $\begin{array}{l}917-756 \\
804 \text { AC }\end{array}$ & $\begin{array}{l}598 \\
765\end{array}$ & GrN-26.093/H \\
\hline $\begin{array}{l}\text { Morro de Mezquitilla. } \\
\text { Corte } 15 . \text { Fosa VIII base. } \\
\text { Calle entre casas K y H. } \\
\text { Fase B 1a }\end{array}$ & $\begin{array}{l}\text { Vélez-Málaga, } \\
\text { Málaga }\end{array}$ & 2750 & 50 & 800 a.C. & $\begin{array}{l}1003 \\
1003\end{array}$ & $\begin{array}{l}932-831 \\
899 \text { AC }\end{array}$ & $\begin{array}{l}811 \\
805\end{array}$ & $\begin{array}{l}\text { B-4178/C? } \\
\text { Mo82-2195 }\end{array}$ \\
\hline $\begin{array}{l}\text { Morro de Mezquitilla. } \\
\text { Corte } 21 \text {. Horno } 3 . \\
\text { Fase B 1a }\end{array}$ & $\begin{array}{l}\text { Vélez-Málaga, } \\
\text { Málaga }\end{array}$ & 2570 & 50 & 620 a.C. & $\begin{array}{l}825 \\
825\end{array}$ & $791 \mathrm{AC}$ & $\begin{array}{l}540 \\
540\end{array}$ & $\begin{array}{l}\text { B-4180/C? } \\
\text { Mo82-2461 }\end{array}$ \\
\hline
\end{tabular}

Tab. 1 [2]. Dataciones más antiguas de la presencia fenicia en Túnez y la Península Ibérica. Tipos de muestras: C: Carbón (Charcoal). H: Hueso (Bone). S: Semillas (Seeds). Fuentes: Arancibia et al. (2011: 137, tab. 1), Fernández Flores y Rodríguez Azogue (2007: 103-104), Marzoli et al. (2010: 174-175, tabs. 1-3), Nijboer y van der Plicht (2006: 32, tab. 1, 33, tab. 2), Sánchez et al. (2012: 69-70, fig. 2-4 y com. pers.). Curva de calibración intcal13, Calib v. 7.0.3. según Reimer et al. (2013) comparada con curva de calibración Intcal98, Calib v. 4.2 según Stuiver et al. (1998).

adobes que separa las habitaciones A-46 y A-45 (Fernández y Rodríguez 2007: 94-104, fig. 5-13). Un siglo después parece fundarse el yacimiento fortificado de Alcorrín (Manilva, Málaga), con un posible santuario en su interior de inspiración fenicia, cuya banda cronológica, en la fortificación interior (968-797 cal AC) y exterior (903-787 cal AC), apunta de fines del siglo IX al primer cuarto del siglo VIII cal AC, o incluso todo el siglo VIII cal AC como sugieren los excavadores (Marzoli et al. 2010: 174-175, tab.1) (Tab. 1).

Hasta la obtención de las dataciones citadas, la presencia fenicia más antigua en la Península Ibérica se había vinculado a Morro de Mezquitilla de cuya fase B1a, procede B-4.178 2750 $\pm 50 \mathrm{BP}$ (Schubart 1983: 130), 1003 [899] 805 cal AC, que resulta muy antigua. En cambio, del corte 7, otra datación de la fase BI, GrN-8.109 2580 \pm 35 BP (Pingel 2006: 147), 801 [794] 596 cal AC, se aproxima mejor a la cronología cerámica de la fase B1 de Morro de Mezquitilla, inicios del siglo VIII AC (Schubart 1986: 68-78; Mederos y Ruiz Cabrero 2006: 132).

Los yacimientos fenicios más antiguos de la Península Ibérica (Huelva, La Rebanadilla y El
Carambolo) presentan un mismo horizonte arqueológico, definido por la asociación de importaciones tirias, griegas del Geométrico Medio, sardas nurágicas y en el caso de Huelva villanovianas, con dataciones radiocarbónicas similares. En Utica documentamos dataciones absolutas calibradas semejantes a las de estos asentamientos junto al mismo horizonte de importaciones mediterráneas, además de producciones de la Península Ibérica. Aun dejando a un lado las dataciones de Huelva Méndez Núñez por las condiciones de recuperación de la muestra, resulta evidente que la serie radiocarbónica de Utica refuerza la de La Rebanadilla (Málaga). Ambas series de dataciones nos parecen suficientemente precisas por ser excavaciones recientes, en dos áreas geográficas distintas, bien contextualizadas arqueológicamente, sobre muestras de vida corta por AMS (en el caso de Útica) y procedentes de dos laboratorios distintos, Centro Nacional de Aceleradores (Sevi1la) y Beta Analityc.

Las series de dataciones de Utica y La Rebanadilla vienen a proponer unas fechas del último cuarto del siglo $\mathrm{X}$ cal $\mathrm{AC}$, o en todo caso en un pleno siglo IX cal AC, para este horizonte inicial 
de la presencia fenicia en el Mediterráneo Central y Occidental. Esta fecha es coherente con la secuencia de las series de dataciones algo más recientes de la Península Ibérica y de Cartago y también con el registro cerámico, más antiguo también en Utica y La Rebanadilla que en la fase más antigua de Morro de Mezquitilla o que los materiales cerámicos más antiguos conocidos de Cartago.

\section{DISCUSIÓN Y CONCLUSIONES}

Las excavaciones del proyecto tunecino-español en Utica aportan datos muy interesantes sobre el horizonte inicial de la colonización fenicia en el Mediterráneo Central y Occidental, en concreto los procedentes de un pozo de agua asociado a un edificio en curso de investigación. El análisis preliminar del conjunto cerámico depositado en el interior del pozo 20017 muestra que se trata de una deposición bastante homogénea y muy poco separada en el tiempo. La funcionalidad de la cerámica, determinada mayoritariamente por vasos para contener, servir y consumir, así como los abundantes restos de fauna, podrían estar indicando que el pozo se rellenó con restos de banquetes. La presencia de numerosas cerámicas importadas testimoniaría el carácter excepcional de la deposición, que posiblemente formara parte de un ritual de clausura, constatado en otros pozos fenicios de Motya ya mencionados.

La asociación de cerámicas registrada en el pozo 20017 de Utica es extraordinaria y constituye hasta ahora el conjunto más numeroso y variado de cerámicas egeas y fenicias orientales conocido en el Mediterráneo Central y Occidental. Además es la colección más amplia de vasos del Geométrico hallada fuera de Grecia, seguida por Tiro en Oriente. En Utica están presentes muchas de las decoraciones del geométrico ático, así como las eubeas de semicírculos colgantes y los vasos monócromos, no muy comunes en Occidente. También hay una facies decorativa como los triángulos cuadriculados, desconocida hasta ahora en Occidente. El hallazgo de cerámicas griegas con decoración del Geométrico Inicial o Medio junto a copas decoradas con semicírculos colgantes del Subprotogeométrico eubeo se registra en Utica, a semejanza de Huelva y Veio. En Oriente esta asociación está presente en los estratos IX-
VIII de Tiro (Bikai 1978: pl. XXIV) y en los ajuares de las tumbas 1 de Salamina (Coldstream 1963; Desborough 1963) y 149 NW de Amathonte (Coldstream 1995) en Chipre.

La existencia de platos con semicírculos colgantes en Tiro, Chipre y Huelva, una forma casi inexistente en Grecia, para Coldstream (2011) indica una producción específica destinada exclusivamente a ambientes fenicios, seguramente a través de Tiro. Este hecho, junto a la variada composición del conjunto de cerámicas geométricas y subprotogeométricas de Utica, nos hace reflexionar sobre el papel esencial de los fenicios en la distribución de las cerámicas geométricas del Geométrico Medio y el Subprotogeométrico en Chipre, Etruria meridional, Campania, Norte de África, Cerdeña y la Península Ibérica, al menos hasta la fundación de Pithecoussa. En este tráfico, Utica debió desempeñar un lugar muy destacado. Las producciones villanovianas que aparecen en Utica formando parte de este contexto, también están en Huelva, mientras que en Utica se conocen cerámicas del Bajo Guadalquivir que no llegan a Italia, aunque sí al norte de Cerdeña: nuraghe de Santu Antine (Torralba) (Madau 1986: 95-96, tav. XVIII: 2, 1988: 246, fig 1: 6-8). Todo ello incide en la atribución de un papel relevante o director de Utica en los circuitos de relaciones entre ambos extremos del Mediterráneo.

La presencia de abundantes producciones sardas relacionadas con el consumo de bebidas resulta muy significativa del papel de Cerdeña en las relaciones de intercambio fenicias más tempranas. Ya señalaban su protagonismo el hallazgo de Sant'Imbenia o la difusión en la Península Ibérica de producciones sardas (Botto 2011). La inclusión en el conjunto del pozo 20017 de cerámicas libias autóctonas, así como la temprana imitación local de formas fenicias y no de otra procedencia aparentemente, podría estar apuntando a unas relaciones estrechas y consolidadas entre fenicios y libios en Utica en una fecha temprana.

La cronología del conjunto, en términos convencionales, podría llegar al último cuarto o a finales del siglo IX a.C., considerando además por separado las dataciones de cada una de las clases de producciones cerámicas en sus áreas de procedencia. El contexto que actualmente se investiga en Utica resulta, en consecuencia, aproximadamente unos 75 o 100 años más antiguo que la fecha tradicionalmente atribuida a la fundación

Trab. Prehist., 73, N. ${ }^{\circ}$ 1, enero-junio 2016, pp. 68-89, ISSN: 0082-5638

doi: $10.3989 /$ tp.2016.12164 
de Cartago por las fuentes clásicas, hacia el 820 a.C., así como a las dataciones absolutas actualmente disponibles en Cartago (Nijboer y van der Plicht 2006: 33, tab. 2), entre el 830-805 cal AC. La antigüedad de Utica, que precede un centenar de años a la de Cartago, se repite también en las dataciones absolutas del pozo 20017, que vienen a ser contemporáneas con las series de dataciones de C14 de Huelva, a pesar de sus problemas contextuales, y con las bien estratificadas de La Rebanadilla y El Carambolo. En conjunto definen los inicios de la colonización fenicia en fechas muy antiguas como un fenómeno de gran alcance que se constata en Túnez y la Península Ibérica y que integra Cerdeña y Etruria meridional y Campania en la Península Itálica.

Las implicaciones cronológicas de la asociación de materiales arqueológicos de Utica y La Rebanadilla a sus respectivas fechas son de una gran relevancia, no sólo para la datación de los inicios de la colonización fenicia, sino también para revisar la correlación de las cronologías de la cerámica geométrica del Geométrico Medio en el Mediterráneo. Diferentes investigadores han venido sugiriendo esa necesidad en los últimos años. Mederos (2005: 329, tabla 13) sitúa el inicio del Geométrico Medio hacia el $875 \mathrm{cal} \mathrm{AC}$, Trachsel (2008: 69, fig. 4.8) entre el 915/850 cal AC o Brandherm (2008: 167, fig. 9.12) en el 860 cal AC. Asimismo, las series de dataciones absolutas de Utica y La Rebanadilla invitan a revisar la correlación habitual de la cerámica griega con la estratigrafía de Tiro. Han propuesto ya su revisión cronológica al alza Schreiber (2003: 208) y Mederos (2005: 333-335 tabla 16), así como Bikai (2003: 234) para los estratos VI-VII, fechados en un siglo IX a.C. avanzado y IV-V que pasaría a 800-750 a.C. La posibilidad de ampliar los resultados arqueológicos y obtener nuevas dataciones radiocarbónicas confiere una alta potencialidad a las aportaciones del proyecto en curso en Utica, al debate cronológico y al conocimiento del periodo de la primera presencia fenicia estable en el Mediterráneo central y occidental.

\section{AGRADECIMIENTOS}

Este trabajo se enmarca en las actividades del Campus de Excelencia Internacional CEI-Mar. Es resultado del proyecto de investigación HAR201129880: "La ciudad fenicio-púnica de Utica y la presencia fenicia en el Norte de África", financiado por el Ministerio de Economía y Competitividad. Los trabajos de campo de 2010 y 2102 del "Proyecto Utica" han sido subvencionados por el programa de excavaciones arqueológicas en el exterior del Ministerio de Educación y Cultura. Agradecemos la extraordinaria labor desarrollada por el equipo del "Proyecto Utica": A. Adroher, B. Alemán, F. Arbi, K. Bennour, J. L. Cardoso, S. Carpintero, F. Dridi, C. Dibhi, F. Esaadi, E. Ferrer, I. Fumadó, K. Jendoubi, W. Khalfalli, M. López-Gay, G. Maldonado, B. Mora, A. Niveau, I. Noussa, C. Pardo, V. Peña, L. Ruiz, A. Sánchez, H. Selimi y S. Souissi. Los autores agradecen también la ayuda logística y la infraestructura prestadas por el Institut National du Patrimoine de Túnez.

\section{BIBLIOGRAFÍA}

Alvar Ezquerra, J. y González Wagner, C. 1985: “Consideraciones históricas sobre la fundación de Cartago". Gerión 3: 79-95.

Andrioménou, A. 1984: "Skyphoi de l'atelier de Chalkis (fin Xe - fin VIIIe s. av. J.-C.)". Bulletin de Correspondance Hellénique 108: 37-69.

Andrioménou, A. 1985: "Skyphoi de l'atelier de Chalkis (fin Xe - fin VIIIe s. av. J.-C.) (II)". Bulletin de Correspondance Hellénique 109: 49-75.

Andrioménou, A. 1986: "Vases protogéométriques et Sub-protogéométriques I-II de l'atelier de Chalcis". Bulletin de Correspondance Hellénique 110: 89-120.

Arancibia, A.; Galindo, L.; Juzgado, M.; Dumas, M. y Sánchez Sánchez-Moreno, V. M. 2011: “Aportaciones de las últimas intervenciones a la arqueología fenicia de la Bahía de Málaga". En M. Alvarez Martí-Aguilar (ed.): Fenicios en Tartessos: nuevas perspectivas (Málaga 2008). British Archaeological Reports, International Series 2245. Oxford: 129-149.

Aubet, M. E. y Núñez, F. J. 2008: "Cypriote imports from the Phoenician cemetery of Tyre, al- Bass". En C. Doumet-Serhal (ed.): Networking patterns of the Bronze and Iron Age Levant: The Lebanon and its Mediterranean connections. Archaeology and History in the Lebanon, Special Edition. ACPP. Beirut: 71-104.

Ayalon, E. 1995: "The Iron Age II Pottery Assemblage from Korvat Teiman (Kuntillet 'Ajrud) Pottery". Tel Aviv 22 (2): 141-205. 
Ben Jerbania, I. 2013: “Observations préliminaires sur la céramique archaïque d'Utique". En J.-Y. Monchambert, I. Ben Jerbania, M. Belarbi, L. Bonadies, H. Bricchi-Duhem, M. De Jonghe, Y. Gallet, J. Yamen Sghaïer, A. Tekki, E. Thébault y S. Vermeulen: "Utique. Rapport préliminaire sur les deux premières campagnes de fouilles de la mission franco-tunisienne, 2011 et 2012". Cronique des activités archéologiques de l'École Française à Rome 2013: 45-50 http://cefr.revues.org/996 (consulta 15I-2016).

Ben Jerbania, I. y Redissi, T. 2014: "Utique et la Méditerranée centrale à la fin du IXe s. et au VIIIe s. av. J.-C.: les enseignements de la céramique grecque géometrique". Rivista di Studi Fenici 42, (2): 177-204.

Bikai, P. M. 1978: The pottery of Tyre. Aris \& Phillips. Warminster.

Bikai, P. M. 1983: The Phoenician Pottery of Cyprus. Leventis Foundation. Nicosia.

Bikai, P. M. 2003: "Statistical observations on the Phoenician pottery of Kition". En V. Karageorghis (ed.): Kition VI, II: The Phoenician and Later Levels. Department of Antiquities. Cyprus. Nicosia: 231-257.

Boitani, F. 2005: "La ceramica greco-geometrica di Veio". En G. Bartoloni y F. del Pino (eds.): Oriente e Occidente: metodi e discipline a confronto. Riflessioni sulla cronologia dell'età del ferro italiana (Roma 2003): 319-332. Roma.

Botto, M. 2007: "Da Sulky a Huelva: considerazioni sui commerci fenici nel Mediterraneo antico". Annali di Archeologia e Storia Antica N.S. 11-12, 2004-05: 9-27.

Botto, M. 2011: "Interscambi e interazioni culturali fra Sardegna e Peninsola Iberica durante i secoli iniziali del I millennio a.C.”. En M. Álvarez Martí-Aguilar (ed.): Fenicios en Tartessos: nuevas perspectivas (Málaga 2008). British Archaeological Reports, International Series 2245. Oxford: 33-67.

Brandherm, D. 2008: "Greek and Phoenician potsherds between East and West: a chronological dilemma?". En D. Brandherm y M. Trachsel (eds.): A new dawn for the Dark Age? Shifting paradigms in Mediterranean Iron Age Chronology. Union Internationale des Sciences Préhistoriques et Protohistoriques. Proceedings of the $X V$ World Congress (Lisbon 2006). British Archaeological Reports International Series 1871. Oxford: 149-174..

Bronk Ramsey, C. 2009: "Bayesian Analysis of Radiocarbon dating". Radiocarbon 51 (1): 337-360.

Campus, F. y Leonelli, V. 2000: La tipologia della ceramica nuragica. Il materiale edito. Ministerio per i Beni e la attivitá culturale-Soprintendenza Archeologica per le province di Sassari e Nuoro. Sassari.

Campus, F. y Leonelli, V. 2006: "La Sardegna nel Mediterraneo fra l'Età del bronzo e l'Età del Ferro. Proposta per una distinzione in fasi”. Studi di
Protostoria in onore di Renato Peroni. All'Insegna dell Giglio. Firenze: 372-392.

Campus, F. y Leonelli, V. 2012: "Tra Bronzo Finale e I Ferro. Analisi dei contesti sardi alla luce del riesame del sitio dell'Ausonio II di Lipari'. En P. Bernardini y M. Perra (eds.): I Nuraghi, I Fenici e gli altri. Sardegna e Mediterraneo tra Bronzo Finale e Prima Età del Ferro (Villanovaforru 2007): 142-164. Sassari.

Campus, F.; Leonelli, V. y Lo Schiavo, F. 2010: "La transizione culturale dall'età del bronzo all'età del ferro nella Sardegna nuragica in relazione con l'Italia terrenica". XVII International Congress of Classical Archaeology. Roma 2008. Session: Long-distance contacts and Acculturation in central Italy from 1000 to 700 B.C. Bollettino di Archeologia on line 1, volume speciale: 62-76. http://www.bollettinodiarcheologiaonline.beniculturali.it/ documenti/generale/6_LOSCHIAVO.pdf

Carriazo y Arroquia, J. de M. 1973: Tartessos y El Carambolo. Investigaciones arqueológicas sobre la Protohistoria de la Baja Andalucía. Ministerio de Educación y Ciencia. Madrid.

Casado Ariza M. 2011: “Cerámica grabada tartésica del Carambolo: nuevos testimonios". Spal 20: 93105.

Chambon, A. 1984: Tell El-Fâr'ah 1. L'Âge du Fer. Editions Recherché sur les Civilisations. Paris.

Chapman, S. V. 1972: "A catalogue of Iron Age pottery from the cemeteries of Khirbet Silm, Joya, Qraye and Qasmieh of South Lebanon". Berytus 21: 55-194.

Chelbi, F.; Paskoff, R. y Trousset, P. 1995 : "La baie d'Utique et son évolution depuis l'Antiquité: une réévaluation géoarchéologique". Antiquités Africaines 31: 7-51.

Cintas, P. 1951: "Deux campagnes de fouilles à Utique". Karthago 2: 1-88.

Cintas, P. 1954: "Deux campagnes de fouilles à Utique". Karthago 5: 89-154.

Coldstream, J. N. 1963: "The Chronology of the Attic geometric Vases". En P. Dikaios, "A Royal Tomb at Salamis, Cyprus". Archäologisches Anzeiger 1963: 199-204.

Coldstream, J. N. 1995: "Amathus Tomb NW 194: the Greek Pottery Imports". Report of the Department of Antiquities Cyprus 1995: 187-198.

Coldstream, J. N. 1996: "The Protogeometric and Geometric pottery". En J. N. Coldstream y H.W. Catling (eds.): Knossos North Cemetery Early Greek Tombs. II. Discussion. The British School at Athens, Supplementary volume 38. Athens: 311-419.

Coldstream, J. N. 2008: Greek Geometric Pottery. A survey of ten local styles and their chronology (Updated Second Edition). Phoenix Press. Bristol.

Coldstream, J.N. 2011: "Far-flung Phoenicians bearing early Greek pottery?". En M. Hartmut, N. Oettinger y S. Schröder (eds.): Der Orient und die Anfänge Europas: kulturelle Beziehungen von der Späten

Trab. Prehist., 73, N. ${ }^{\circ}$ 1, enero-junio 2016, pp. 68-89, ISSN: 0082-5638

doi: $10.3989 /$ tp.2016.12164 
Bronzezeit bis zur Frühen Eisenzeit (Erlangen 2006): 177-184. Wiesbaden.

Colozier, E. 1954: "Nouvelles fouilles à Utique". Karthago 5: 156-161.

Córdoba, I. y Ruiz Mata, D. 2005: "El asentamiento fenicio arcaico de la calle Cánovas del Castillo (Cádiz). Un análisis preliminar". En S. Celestino y J. Jiménez Ávila (eds.): El periodo orientalizante. III Simposio Internacional de Arqueología de Mérida (Mérida 2003), II. Anejos de Archivo Español de Arqueología 33, Instituto de Arqueología de Mérida y Consejo Superior de Investigaciones Científicas. Madrid: 1269-1322.

Crowfoot, J. W.; Crowfoot, G. M. y Kenyon, K. M. 1957: Samaria-Sebaste III. The objects from Samaria. Palestine Exploration Fund. London.

D’Agostino, B. 1990: "Relations between Campania, Southern Etruria and Aegean in the Eighth Century BC'. En J. P. Descoeudres (ed.): Greek Colonists and Native Populations. Proceedings Australian Congress Classical Archaeology (Sydney 1985): 73-85. Canberra-Oxford.

Desborough, V. R. d'A 1963: "The low footed skyphoi with pendent semicircles". En P. Dikaios, "A Royal Tomb at Salamis, Cyprus". Archäologischer Anzeiger 1963: 204-206.

Descoudres, J. P. y Kearsley, R. 1983: “Greek Pottery at Veii: Another Look". Annual of the British School at Athens 78: 9-53.

Docter, R. F.; Annis, M. D.; Jacobs, L. y Blessing, G. H. J. M. 1997: "Early Central Italian Transport Amphorae from Carthage: Preliminary Results". Rivista di Studi Fenici 25: 15-58.

Escacena, J. L.; Fernández Flores, A. y Rodríguez Azogue, A. 2007: "Sobre el Carambolo: un híppos sagrado del santuario IV y su contexto arqueológico". Archivo Español de Arqueología 80: 5-28.

Fernández Flores, A. y Rodríguez Azogue, A. 2007: Tartessos desvelado. La colonización fenicia del Suroeste peninsular y el origen y ocaso de Tartessos. Almuzara. Córdoba.

Finkelstein, I.; Zimhoni, O. y Kafri, A. 2000: "The Iron Age Pottery Assemblages from Areas F, K, and $\mathrm{H}$ and their Stratigraphic and Chronological Implication". En I. Finkelstein, D. Ussishkin y B. Halpern (eds.): Megiddo III. The 1992-1996 seasons. Institute of Archaeology Series 18. Tel Aviv: 244-324.

Fundoni, G. 2009: "Le relazioni tra la Sardegna e la Peninsola Iberica nei primi secoli del I millennio a.C.: le testimonianze nuragiche nella Penisola Iberica". Anales de Arqueología Cordobesa 20: 11-34.

Gastaldi, P. 1998: Pontecagnano. II. 4. La necropoli del Pagliarone. Annali del Dipartamento di Studi del Mondo Classico e del Mediterraneo Antico 10, Istituto Universitario Orientale. Napoles.

Gilboa, A. 2013: “À-propos Huelva: a reassessment of 'Early' Phoenician in the West'. En J. Campos y J.
Alvar (eds.): Tarteso. El emporio del metal (Huelva 2011): 311-342. Almuzara, Córdoba.

Gimatzidis, S. 2010: Die Stadt Sindos. Eine siedlung von der später bronze- bis zur klassischen Zeit am thermaischen golf in Makedonien. Prähistorische Archäologie in Südosteuropa 26, Verlag Marie Leidorf GMBH. Rahden/Westf.

Gjerstaad, E. 1960: "Pottery Types. Cypro-Geometric to Cypro-Classical". Opuscula Atheniensia 3: 105122.

Gómez Toscano, F.; Linares, J. A. y Haro, J. de 2009: "Fondos de cabaña del Bronce Final-Orientalizante en la tierra llana de Huelva”. En J. A. Pérez Macias y E. Romero (eds.): IV Encuentro de Arqueología del Suroeste Peninsular (Aracena, Huelva 2008): 606-647. Huelva. CD-rom.

Gonzalez de Canales, F.; Serrano Pichardo, L. y Llompart Gómez, J. 2004: El emporio fenicio precolonial de Huelva (ca. 900-770 a.C.). Biblioteca Nueva. Madrid.

Groenewoud, E. M. C. 2001: "Use of Water in Phoenician Sanctuaries". Ancient Near Eastern Studies 38: 139-159.

Guidi, A. 1980: Studi sulla decorazione metopale nella cerámica villanoviana. Biblioteca di Studi Etruschi 13, Istituto di Studi Etruschi ed Italici. Leo S. Olschki. Firenze.

Hay, S.; Fentress, E.; Kallala, N.; Quinn, J. y Wilson, A. 2010: "Utica". Papers of the British School at Rome 78: 325-329.

Hencken, H. 1968: Tarquinia, Villanovians and Early Etruscans. Bulletin of the American School of Prehistoric Research 23, Peabody Museum. Cambridge, Mass.

Herrera, Ma D. y Gómez Toscano, F. 2004: Tell Abu Hawam (Haifa, Israel). El horizonte fenicio del Stratum III británico. Universidad Pontificia de Salamanca-Universidad de Huelva. Huelva.

Kearsley, R. 1989: The Pendent semi-circle Skyphos. Bulletin Supplement 44, Institute of Classical Studies. London.

Kollund, M. 1992-93: "Sea and Sardinia. Interactions in the Iron Age: Phoenicians, Greeks and the Indigenous Peoples of the Western Mediterranean". Hamburger Beiträge zur Archäologie 19-20: 201-214.

Kourou, N. 2005: "Greek imports in Early Iron Age Italy”. En G. Bartoloni y F. del Pino (eds.): Oriente e Occidente: metodi e discipline a confronto. Riflessioni sulla cronologia dell'età del ferro italiana (Roma 2003): 497-516. Roma.

Lézine, A. 1968: Carthage, Utique. Etudes d'architecture et d'urbanisme. Centre National de la Recherche Scientifique. Paris.

Lo Schiavo, F. 2005: "Le brochette askoidi nuragiche nel Mediterraneo all'alba della storia". Sicilia Archeologica 38 (103): 101-116.

López Castro, J. L.; Ferjaoui. A.; Peña Ruano, J. A.; Teixidó Ullod, T.; Ghazouami, M.; Adroher, A. y 
Ben Nejma, M. 2010: "Proyecto Utica. Informe de los trabajos arqueológicos efectuados en la ciudad fenicio-púnica de Utica (Túnez). Campaña de 2010". Informes y trabajos 7: 360-371.

López Castro, J. L.; Ferjaoui, A.; Adroher, A.; Arbi, F; Ben Jerbania, I.; Dridi, F.; Essaadi, F.; Ferrer Albelda, E.; Fumadó, I.; Martínez Hahnmüller, V.; Mederos, A.; Pardo Barrionuevo, C.A.; Peña Romo, V. y Sánchez Moreno, A. 2014: "Proyecto Útica. Investigación en la ciudad fenicio-púnica". Informes y trabajos 11: 201-219.

Madau M. 1986: "Materiali di importazione dalla Sardegna settentrionale". En Società e cultura in Sardegna nei periodi orientalizzante e arcaico. Un millennio di relazioni tra la Sardegna e i Paesi del Mediterraneo, Atti del I Convegno di Studi (Selargius-Cagliari 1985): 95-100. Cagliari.

Madau M. 1988: "Nuraghe S. Antine di Torralba: materali fittili di età feniciopunica". En A. Moravetti (ed.). Il nuraghe S. Antine nel Logudoro-Meilogu. Carlo Delfino Editore. Sassari: 243-271.

Mandolesi, A. 1999: La 'Prima Tarquinia'. L'insediamento protostorico sulla Civita en nel territorio circostante. Grandi contesti e problema della Protostoria italiana 2. All'Insegna del Giglio. Florencia.

Mansel, K. 1999: "Handgemachte Keramik der Siedlungsschichten des 8. und 7. Jahrhunderts v. Chr. aus Karthago. Ein Vorbericht". En F. Rakob (ed.): Karthago III. Die Deutschen Ausgrabungen in Karthago. Phlipp von Zabern. Mainz: 220-238.

Mansel, K. 2007: "Handgemachte Ware und Schwerkeramik". En H. G. Niemeyer, R. F. Docter, K. Schmidt y B. Bechtold (eds.): Karthago. Die Ergebnisse der Hamburger Grabung unter dem Decumanus Maximus. Philipp von Zabern. Mainz: 432-447.

Mansel, K. 2011: Cartago y la Península Ibérica en los siglos VIII - VI a.C. En M. Álvarez Martí-Aguilar (ed.): Fenicios en Tartesos: nuevas perspectivas (Málaga 2008). British Archaeological Reports, International Series 2245. Oxford: 69-85.

Martín Córdoba, E.; Ramírez, J.; Recio, A. y Moreno, A. 2007: "Nuevos yacimientos fenicios en la costa de Vélez-Málaga (Málaga)”. Ballix 3: 7-46.

Marzoli, D.; López Pardo, F.; Suárez, J.; González Wagner, C.; Mielke, D. P.; León, C.; Ruiz Cabrero, L.; Thiemeyer, H. y Torres, M. 2010: "Los inicios del urbanismo en las sociedades autóctonas localizadas en el entorno del Estrecho de Gibraltar: investigaciones en los Castillejos de Alcorrín y su territorio (Manilva, Málaga)". Menga 1: 152-183.

Mederos Martín, A. 2005: "La cronología fenicia. Entre el Mediterráneo Oriental y el Occidental". En S. Celestino y J. Jiménez Ávila (eds.): El periodo orientalizante. III Simposio Internacional de Arqueología de Mérida (Mérida 2003) II. Anejos de Archivo Español de Arqueología 33, Instituto de Arqueología de Mérida y Consejo Superior de Investigaciones Científicas. Madrid: 305-346.
Mederos, A. y Ruiz Cabrero, L. A. 2006: "Los inicios de la presencia fenicia en Málaga, Sevilla y Huelva". Mainake 28: 129-176.

Monchambert, J.Y.; Ben Jerbania, I.; Belarbi, M.; Bonadies, L.; Bricchi-Duhem, H.; De Jonghe, M.; Gallet, Y.; Yamen Sghaïer, J.; Tekki, A.; Thébault, E. y Vermeulen, S. 2013: "Utique. Rapport préliminaire sur les deux premières campagnes de fouilles de la mission franco-tunisienne, 2011 et 2012”. Cronique des activités archéologiques de l'École Française à Rome 2013: http://cefr.revues.org/996 (consulta 15-I-2016).

Nigro, L. 2014: "Il primo stanziamento fenicio a Mozia: Nuovi dati dall'area sacra del Kothon". En A. Lemaire (ed.): Phéniciens d'Orient et d'Occident. Mélanges Josette Elayi. Cahiers de l'Institut du Proche-Orient ancien du Collège de France II, Maissoneuve. Paris: 491-504.

Nigro, L. y Spagnoli, F. 2012: "Alle sorgenti del Kothon". Il rito a Mozia nell'Area sacra di Baal 'Addir - Poseidon. Lo scavo dei pozzi sacri nel Settore C Sud-Ovest (2006-2011). Quaderni di Archeologia Fenicio-Punica Colour Monograph 02. Missione archeologica a Mozia. Roma: 1-63.

Nijboer, A. J. y van der Plicht, J. 2006: “An interpretation of the radiocarbon determinations of the oldest indigenous-Phoenician stratum thus far, excavated at Huelva, Tartessos (south-west Spain)". Bulletin des Antieke Beschaaving 81: 31-36.

Núñez Calvo, F. 2010: "Referencias secuenciales del repertorio cerámico fenicio metropolitano de la Edad del Hierro Tardío". En L. Nigro (ed.): Motya and the Phoenician ceramic repertoire between the Levant and the West, $9^{\text {th }}-6^{\text {th }}$ century BC (Rome 2010): 49-83. Roma.

Núñez Calvo, F. 2014: "Tyrian potters and their products: standardization and variation in the pottery of the al - Bass cemetery". En A. Kotsonas (ed.): Understanding standardization and variation in $\mathrm{Me}$ diterranean ceramics mid $2^{\text {nd }}$ to late $1^{\text {st }}$ Millennium BC. $16^{\text {th }}$ Annual Meeting of the European Association of Archaeologists (The Hague 2010): 59-84. Lovain.

Oggiano, I. 2000: "La ceramica fenicia di S. Imbenia (Algero-SS)". En P. Bartoloni y L. Campanela (eds.): La ceramica fenicia di Sardegna. Dati, Problematiche e Confronti. I Congresso Internazionale Sulcitano (Sant'Antioco 1997): 235-258. Roma.

Pacciarelli, M. 2006: Dal Villaggio alla Città. La svolta protourbana del 1000 a.C. nell'Italia tirrenica. Grandi contesti e problema della Protostoria italiana 4. All'Insegna del Giglio. Borgo San Lorenzo.

Paskoff, R. y Trousset, P. 1992: "L'ancienne baie d'Utique. Du témoignage des textes à celui des images satelitaires". Mappe Monde 1: 30-34.

Pingel, V. 2006: "Comentarios a las dataciones por radiocarbono del Morro de Mezquitilla". En H. Schubart (ed.): Morro de Mezquitilla. El asenta-

Trab. Prehist., 73, N. ${ }^{\circ}$ 1, enero-junio 2016, pp. 68-89, ISSN: 0082-5638

doi: $10.3989 /$ tp.2016.12164 
miento fenicio-púnico en la desembocadura del río Algarrobo. Anejos de Mainake 1, Diputación de Málaga. Málaga: 147-151.

Ramon Torres, J. y Maraui Telmini, B. 2011: "Les sondages dans la Zone 2". En N. Kallala y J. Sanmartí (eds.): Althiburos I. la fouille dans l'aire $d u$ capitole et dans la nécropole méridionale. Institut Català d'Arqueologia Clàssica-Institute National du Patrimoine. Tarragona: 153-393.

Reimer, P. J.; Baillie, M.G.L.; Bard, E.; Bayliss, A.; Beck, J. W.; Bertrand, C. J. H.; Blackwell, P.G.; Buck, C. E.; Burr, G. S.; Cutler, K. B.; Damon, P. E.; Edwards, R. L.; Fairbank, R. G.; Friedrich, M.; Guilderson, T. P.; Hogg, A. G.; Hughen, K. A.; Kromer, B.; McCormac, G.; Manning, S. W.; Bronk Ramsey, C.; Reimer, R. W.; Remmele, S.; Southon, J. R.; Stuiver, M.; Talamo, S.; Taylor, F. W.; van der Plicht, J. y Weyhenmeyer, C. E. 2004: "IntCal04 Terrestrial Radiocarbon Age Calibration, 0-26 cal kyr BP". Radiocarbon 46 (3): 1029-1058.

Reimer, P. J.; Baillie, M. G. L.; Bard, E.; Bayliss, A.; Beck, J. W.; Blackwell, P. G.; Bronk Ramsey, C.; Buck, C. E.; Burr, G. S.; Edwards, R. L.; Friedrich, M.; Grootes, P. M.; Guilderson, T. P.; Hajdas, I.; Heaton, T. J.; Hogg, A. G.; Hughen, K. A.; Kaiser, K. F.; Kromer, B.; McCormac, G.; Manning, S. W.; Reimer, R. W.; Richards, D. A.; Southon, J. R.; Talamo, S.; Turney, C. S. M.; van der Plicht, J. y Weyhenmeyer, C. E. 2009: "IntCal09 and Marine09 Radiocarbon Age Calibration Curves, 0-50,000 years cal BP". Radiocarbon 51 (4): 1111-1150.

Reimer, P. J.; Bard, E.; Bayliss, A.; Beck, J. W.; Blackwell, P. G.; Bronk Ramsey, C.; Buck, C. E.; Cheng, H.; Edwards, R. L.; Friedrich, M.; Grootes, P. M.; Guilderson, T. P.; Haflidason, H.; Hajdas, I.; Hatté, C.; Heaton, T. J.; Hoffmann, D. L.; Hogg, A. G.; Hughen, K. A.; Kaiser, K. F.; Kromer, B.; Manning, S. W.; Niu, M.; Reimer, R. W.; Richards, D. A.; Scott, E. M.; Southon, J. R.; Staff, R. A.; Turney, C. S. M. y van der Plicht, J. 2013: "IntCal13 and Marine13 Radiocarbon Age Calibration Curves 0-50.000 years cal BP”. Radiocarbon 55 (4): 1869-1887.

Ruiz Mata, D. 1995: "Las cerámicas del Bronce Final. Un soporte tipológico para delimitar el tiempo y el espacio tartésico". Tartessos. 25 años después 19681993 (Jerez de la Frontera 1993): 265-313. Jerez.

Ruiz Mata, D. 1999: "La fundación de Gadir y el Castillo de Doña Blanca: contrastación textual y arqueológica". Complutum 10: 279-317.

Sagona, A. 1982: "Levantine storage jars of the 13th to 4th Century B. C.". Opuscula Atheniensia 14: 73-110.

Sánchez Manzano, M. A. 2001: "Introducción”. Veleyo Patérculo, Historia Romana. Biblioteca Clásica Gredos 284. Gredos. Madrid: 7-41.

Sánchez Sánchez-Moreno, V.; Galindo, L.; Juzgado, M. y Dumas, M. 2012: "El asentamiento fenicio de La
Rebanadilla a finales del siglo IX A.C.”. En E. García Alfonso (ed.): Diez años de Arqueología Fenicia en la provincia de Málaga (2001-2010). María del Mar Escalante Aguilar in memoriam. Monografías Arqueología, Junta de Andalucía. Málaga: 67-85.

Sanges, M. 2007: "Brindisi nuragici nell'isola del vino: i dati archeologici sul vino in Sardegna". Darwin Quaderni 3: 17-22.

Schreiber, N. 2003: The Cypro-Phoenician Pottery of the Iron Age. Culture and History of the Ancient Near East 13. Brill. Leiden-Boston.

Schubart, H. 1983: "Morro de Mezquitilla. Vorbericht über die Grabungskampagne 1982 auf dem Siedlungshügel an der Algarrobo-Mündung". Madrider Mitteilungen 24: 104-131.

Schubart, H. 1986: "El asentamiento fenicio del s. VIII a.C. en el Morro de Mezquitilla (Algarrobo, Málaga". En G. del Olmo y M. E. Aubet (eds.): Los fenicios en la Península Ibérica. I. Arqueología, cerámica y plástica. Ausa. Sabadell: 59-83.

Serbat, G. 1995: "Introducción general". Plinio el Viejo, Historia Natural. Libros I-II. Biblioteca Clásica Gredos 206, Gredos. Madrid: 7-206.

Spagnoli, F. 2014: "Phoenician cities and water: The role of the sacred sources in the urban development of Motya, Western Sicily". En T. Tvedt y T. Oestigaard (eds.): Water and Urbanization. A history of water series III,1. I.B. Tauris. Londres-Nueva York: 89-106.

Torres Ortiz, M. 2004: "Un fragmento de vaso askoide nurágico del fondo de cabaña del Carambolo". Complutum 15: 45-50.

Trachsel, M. 2008: "Steps towards a revised chronology of Greek Geometric pottery". En D. Brandherm y M. Trachsel (eds.): A new dawn for the Dark Age? Shifting paradigms in Mediterranean Iron Age Chronology. Union Internationale des Sciences Préhistoriques et Protohistoriques. Proceedings of the XV World Congress (Lisbon 2006). British Archaeological Reports International Series 1871. Oxford: 59-75.

Vagnetti, L. 1989: "A Sardinian Askos from Crete". The Annual of the British School at Athens 84: 355360.

Verdan, S.; Kenzelmann Pfyffer, A. y Léderrey, C. 2008: Céramique géométrique d'Érétrie. Eretria XX. Fouilles et recherches. École suisse d'archéologie en Grèce. Atenas.

Yadin, Y.; Aharoni, Y.; Amiran, R.; Dothan, T.; Dunayevsky, I. y Perrot, J. 1958: Hazor I. The First Season 1955. The Magnes Press. Jerusalén.

Yadin, Y.; Aharoni, Y.; Amiran, R.; Dothan, T.; Dunayevsky, I. y Perrot, J. 1960: Hazor II. The Second Season 1956. The Magnes Press. Jerusalén.

Yadin, Y.; Aharoni, Y.; Amiran, R.; Dothan, T.; Dunayevsky, I. y Perrot, J. 1961: Hazor II. The Third and Fourth Seasons 1957-1958. The Magnes Press. Jerusalén. 